\title{
Del $<$ Kaschibo $>$ de Tessmann al cashibo-cacataibo contemporáneo: algunas notas para la comprensión de la historia lingüística de un pueblo pano ${ }^{1}$
}

Roberto Zariquiey Biondi ${ }^{2}$

\begin{abstract}
Resumen
En su clásico volumen de 1930, Günter Tessmann ofrece una lista léxica del idioma $<$ Kaschibo $>$, que corresponde a la lengua que actualmente se conoce, entre otras denominaciones, como cashibo-cacataibo. La lista de Tessmann ofrece 31 palabras en los tres dialectos <Kaschibo> que el autor identifica más 81 entradas con información solo sobre uno de ellos: <Kaschinõ>). En el presente artículo ofrecemos un estudio comparativo de los materiales de Tessmann a partir de datos contemporáneos sobre los distintos dialectos de cashibo-cacataibo (Zariquiey 2011b). La comparación nos enfrentará a problemas de interpretación sumamente interesantes y, a la vez, nos permitirá descubrir algunos cambios fonéticos y fonológicos relevantes para la comprensión de la diacronía de esta lengua pano.
\end{abstract}

Palabras clave: cashibo-cacataibo, pano, lenguas amazónicas, dialectología, Günter Tessmann.

\section{Resumo}

No seu clássico volume de 1930, Günter Tessmann oferece uma lista de palavras do idioma "Kaschibo", que corresponde à língua que atualmente se conhece, dentre outras denominações, como "Cashibo-cacataibo". A lista de Tessmann oferece 31 palavras nos três dialetos "Kaschibo" identificados pelo autor, além de 81 entradas com informação apenas em um deles: "Kaschinõ". No presente artigo oferecemos um estudo comparativo dos materiais de Tessmann, partindo dos dados contemporâneos sobre os diferentes dialetos de Cashibo-cacataibo (Zariquiey 2011b). A comparação nos colocará frente a frente com alguns problemas de interpretação sumamente interessantes e, por sua vez, permitir-nos-á descobrir algumas mudanças fonéticas e fonológicas relevantes para a compreensão da diacronia dessa língua Pano.

Palavras-chave: Cashibo-cacataibo. Pano. Línguas Amazônicas. Dialetologia. Günter Tessmann.

1 Quisiera agradecer a los hablantes de cashibo-cacataibo que gentilmente colaboraron conmigo en la elaboración de la lista comparativa empleada en este artículo: Emilio Estrella, Ricardo Odicio, Salomón Estrella, Wilder Bonzano, Leila Bonzano, José Mosolino, Francisco Mosolino, Ricardo Pereira, Alfredo Estrella y Raúl Angulo.

2 Pontificia Universidad Católica del Perú. E-mail: rzariquiey@pucp.edu.pe 


\section{Introducción}

En 1930, el etnógrafo alemán Günter Tessmann publicó su ya clásico volumen Die Indianer Nordost-Perus (Los indígenas del Perú nororiental). En este libro, el autor presentó los resultados de un ambicioso proyecto de investigación emprendido algunos años antes (entre 1921 y 1926), que tenía por objetivo ofrecer una visión etnográfica de conjunto de una de las regiones menos conocidas del mundo en ese entonces: la Amazonía peruana.

Su libro está compuesto de tres partes. En la primera, el autor presenta algunos lineamientos metodológicos generales para el estudio de las culturas (con énfasis en Sudamérica) y explica algunos detalles acerca de su propio trabajo de campo. En la segunda parte, que es probablemente la que ha tenido más trascendencia entre los estudiosos de los pueblos amazónicos y sigue siendo fuente obligatoria de consulta hasta la fecha, Tessmann ofrece notas etnográficas sobre 50 grupos étnicos de la Amazonía peruana. Algunas de estas notas son altamente informativas y constituyen documentos de un alto valor antropológico y lingüístico. Para su elaboración, Tessmann preparó un cuestionario que incluye 76 tópicos etnográficos (vinculados a religión, cultura material, parentesco, tipos de vivienda, etc.) y lo aplicó de manera rigurosa con los distintos pueblos con los que tuvo contacto. Siempre que le fue posible, Tessmann incluyó información sobre cada uno de estos temas para cada grupo étnico que documentó. El último de los puntos incluidos en cuestionario de Tessmann era una lista léxica. La lista léxica diseñada por Tessmann estaba divida en dos secciones: la primera constaba de 33 términos "básicos" que el autor recogió, con algunos vacíos, para prácticamente todos los pueblos estudiados; la segunda, por su parte, añadía otros aproximadamente 200 términos que el autor intentó completar con los pueblos con los que tuvo la opción de trabajar por un tiempo más prolongado. No exageramos al decir que el esfuerzo de Tessmann por elaborar estas listas ha rendido muchos frutos: ellas han sido y son actualmente objeto de estudios filológicos (ver, por ejemplo, Fleck 2008; Zariquiey en prensa; y, además, el presente estudio). En algunos casos, las listas de Tessmann constituyen la única fuente de datos para variedades linguísticas amazónicas hoy extintas (como es el caso del $<$ Nokamán>, ver Zariquiey en prensa) y, por ello, el trabajo de Tessmann se ha constituido en una de las fuentes más valiosas de datos léxicos sobre lenguas amazónicas de principios del siglo XX.

El presente artículo ofrece un estudio filológico y comparativo de los datos léxicos recogidos por Tessmann para el idioma $<$ Kaschibo $>$ (conocido también en la literatura como cashibo-cacataibo, cacataibo, kakataibo y uni). Los datos de Tessmann sobre este idioma son particularmente ricos. El etnógrafo alemán recogió información sobre 31 de las 33 entradas incluidas en su lista básica para los tres dialectos de <Kaschibo $>$ que identificó: <Kaschinõ $>$, < runõ > 
y <Kakataibo $>$ (aunque con algunos vacíos; ver más abajo) y completó 81 términos más para el primero de los dialectos referidos. Si bien, como es esperable en un trabajo publicado en 1930, el documento de Tessmann presenta algunas incoherencias de diversa índole, se trata en general de un material sumamente interesante que plantea preguntas cruciales para la comprensión de la historia lingüística del pueblo cashibo-cacataibo. En este artículo, nos proponemos observar los datos de Tessmann a la luz de datos sincrónicos sobre los cuatro dialectos de cashibo-cacataibo identificados en Zariquiey (2011b) con la finalidad de intentar establecer asociaciones entre los dialectos que Tessmann encontró y los que existen en la actualidad. A partir de esta comparación, se nos revelarán datos importantes sobre la diacronía del idioma cashibo-cacataibo.

\section{El pueblo cashibo-cacataibo y su lengua}

Antes de iniciar la exposición de las características lingüísticas y dialectológicas más saltantes del idioma cashibo-cacataibo, conviene comentar brevemente el origen de su nombre. La etimología del término cashibo es bastante transparente. Se trata de un término pano (muy probablemente del shipibo-conibo) compuesto de los siguientes elementos: kashi 'murciélago' + -bo 'colectivo' (hecho que el propio Tessmann ya había notado; 1930:124). El hecho de que el término en cuestión provenga del shipibo-conibo no debería de extrañarnos: por lo general, los etnónimos pano contemporáneos provienen de denominaciones que empleaban ciertos pueblos para referirse a otros, dentro de un sistema muy complejo de denominaciones interétnicas. De más está explicar que muchos de los nombres pano que han pervivido hasta la fecha en el Perú fueron acuñados por los pueblos que tuvieron un contacto sostenido con los misioneros o que establecieron sus centros de evangelización en el Ucayali (como los shipibo y los conibo).

El término cacataibo, en cambio, es todavía enigmático. Por ejemplo, Winstrand (1998:xvi) considera que el término significa "wandering people" ("gente errante"), pero, tal como ha sido discutido en detalle en Zariquiey (2011a:45), la etimología que parece estar detrás de la interpretación de Winstrand es probablemente incorrecta (aunque está ciertamente extendida entre los shipibo-conibo hasta la fecha). En realidad, más acertada (aunque todavía misteriosa) parece ser la interpretación ofrecida por el propio Tessmann (1930:128), quien sostiene que el término cacataibo podría significar "buena gente", aunque sugiere que no está totalmente seguro de ese dato. Una interpretación similar del término nos ha sido dada durante nuestro trabajo de campo por diversos ancianos hablantes de la lengua, quienes sostienen que este significa "los mejores hombres". El análisis morfológico correspondiente a ese significado, sin embargo, no es totalmente transparente. Para empezar, 
la terminación - bo está claramente asociada al morfema 'colectivo' que encontramos también en la forma cashibo. Eso nos deja con la forma cacatai que, gramaticalmente, debería ser un elemento nominal (para que pueda recibir la modificación de -bo). Entonces, partiendo de eso, es posible postular la presencia del nominalizador de sujeto -ai (Zariquiey 2011a: cap. 20), que, además, tiene un valor aspectual habitual. Si esto es correcto, como parece serlo, nos quedaría por descubrir la interpretación de la forma cacat. Para poder ser combinada con el nominalizador arriba especificado, cacat-(kakat-) necesita ser una forma verbal, pero desafortunadamente no hay un verbo en cashibo-cacataibo que pueda ser fácilmente asociado con esa forma. Cabe la posibilidad de que estemos ante una forma reduplicada: es decir que tengamos algo como $k a(t) k a t$, donde la caída de la primera $t$ es totalmente predecible. Sin embargo, tampoco es fácil encontrar un correspondiente para la raíz verbal kat- que nos permita obtener un significado similar al atribuido al término. Nuestra única pista es la existencia del termino ka(:)tai, que Shell (1986:28) incluye en su vocabulario cashibo-cacataibo-castellano bajo la definición "la más grande y mejor ave que existe". La forma caatai, tal como es representada ortográficamente por Shell, parece ser la nominalización con -ai de la versión no reduplicada de kat- que podría ser un verbo antiguo con un significado similar al de "ser el mejor de su clase". Sin embargo, no podemos estar seguros de esta interpretación y tampoco tenemos una explicación para el alargamiento vocálico asociado a la forma recién presentada. La pregunta sobre este término sigue abierta a la fecha.

El pueblo cashibo-cacataibo vive actualmente en las regiones peruanas de Huánuco y Ucayali, a lo largo de los ríos Shamboyacu, San Alejandro y Sungaroyacu (aunque, recientemente grupos de cashibo-cacataibo se han mudado al río Pisqui). El mapa que se presenta a continuación localiza las comunidades cashibo-cacataibo tituladas más importantes; No se cuenta con un dato preciso sobre la población cashibo-cacataibo total: según el censo más reciente de comunidades indígenas de la Amazonía peruana (INEI: 2007), los cashibo-cacataibo se cuentan en un número total de 1879; sin embargo, su organización política (FENACOCA) estimaba, hacia el 2007 y de manera extraoficial, que ese número podría estar en realidad entre las 3,000 y las 3,500 personas.

El idioma cashibo-cacataibo pertenece a la familia lingüística Pano, al interior de la cual es la lengua más occidental y más cercana a los Andes. En un estudio comparativo que incluye datos detallados para siete lenguas pano, Shell (1975 [1965]) concluye que este idioma es el más divergente dentro de su muestra (que no incluye suficiente información sobre las lenguas pano del norte). D’Ans (1973) clasifica al cashibo-cacataibo como el único miembro del grupo pano preandino; mientras que, para Fleck (en prensa), el cashibocacataibo constituye por sí solo un subgrupo dentro una rama mayor que el 
Mapa 1. Localización de las comunidades cashibo-cacataibo

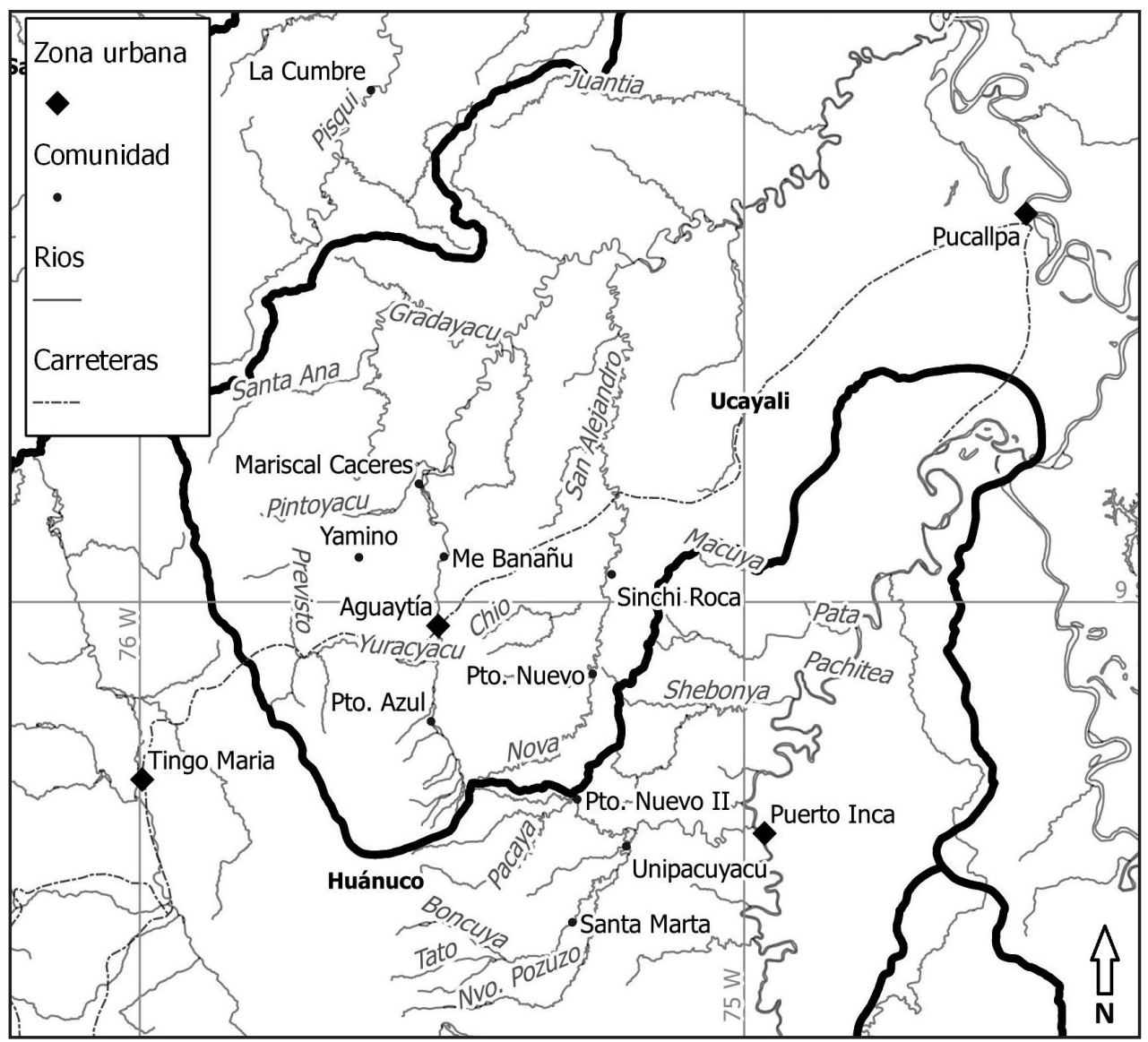

autor denomina "mainline", opuesta en su propuesta a la rama "mayoruna" (que agrupa, únicamente, las lenguas pano norteñas). Loos (1999), por su parte, incluye el cashibo-cacataibo como una lengua no clasificada en su propuesta de organización interna de la familia pano. Si bien encontramos ciertas diferencias en las clasificaciones recién mencionadas, en todas ellas se deja ver la tendencia a considerar al cashibo-cacataibo como la única lengua dentro de su sub-grupo. Esto es una clara muestra de su importancia para la adecuada comprensión de la historia de la familia lingüística pano.

El cashibo-cacataibo es predominantemente posposicional y prácticamente todas las categorías gramaticales son indicadas a través de sufijos, enclíticos y posposiciones; sin embargo, la lengua incluye una clase cerrada de prefijos principalmente relacionados a partes del cuerpo. Además, tiende claramente hacia las estructuras aglutinantes; marca las categorías gramaticales tanto en el núcleo como en los modificadores; presenta un sistema de caso con un alineamiento ergativo-absolutivo en los nombres y uno tripartito en los 
pronombres (que forma parte de un complejo sistema de relaciones gramaticales; Zariquiey 2011c); exhibe concordancia de sujeto en el verbo y en un conjunto cerrado de clíticos de segunda posición que indican modo y otras categorías gramaticales (ambos casos de concordancia se basan en un alineamiento de tipo nominativo-acusativo). El orden de palabras es relativamente libre y orientado pragmáticamente; pero con una fuerte tendencia a presentar oraciones con el verbo al final. No existe un orden rígido en la frase nominal y varios de los modificadores nominales disponibles -incluyendo los adjetivospueden aparecer tanto antes como después del núcleo. Otros rasgos sintácticos llamativos de este idioma son la existencia de un rico sistema de cambio de referencia (switch-reference) y el uso de nominalizaciones como estrategia para satisfacer funciones tales como relativización y complementación.

\section{Dialectología del idioma cashibo-cacataibo}

A pesar del número relativamente reducido de sus hablantes y de la cercanía geográfica entre ellos, el idioma cashibo-cacataibo revela una considerable diversidad dialectal. Tal diversidad fue documentada tempranamente por Günter Tessmann (1930: 128), cuyo trabajo es objeto central del presente artículo. Tal como veremos en más detalle en la siguiente sección, Tessmann clasifica a los cashibo-cacataibo ( $<$ Kaschibo $>$ en su escritura) en tres subgrupos: $<$ Kaschinõ $>$, < runõ $>$ y $<$ Kakataibo $>$, subdivididos a su vez, según el autor, en 18 clanes (ver §4.2). Estudiosos posteriores a Tessmann describen una situación dialectal similar. Lila Wistrand (1969:146-147; 1998:113-114) propone también tres dialectos de cashibo-cacataibo, que ella denomina: cacataibo ('gente cacatai', localizados en el río San Alejandro); canabae uni ('gente guacamayo', ubicados en el Bajo Aguaytía); y rubu ('gente mono aullador', ubicados en el Alto Aguaytía). Wistrand (1969:147) explica que, en este último grupo, debe incluirse a los isunobu ('gente mono araña', localizados en el río Sungaroyacu y áreas cercanas), quienes representan un cuarto subgrupo dentro del pueblo cashibo-cacataibo, pero lingüísticamente son sumamente similares a los cashibo-cacataibo del Alto Aguaytía. Esa es probablemente la razón por la cual Tessmann solo documenta tres grupos y no cuatro. En realidad, la propia Winstrand, que habla de este cuarto grupo, indica que no hay necesidad ni lingüística ni cultural de separar a los que la autora denomina rubu de los que ella misma refiere como isunobu. Un estudio más reciente (Zariquiey 2011b) reconoce la misma situación, pero señala algunas ligeras diferencias lingüísticas entre estos dos últimos grupos.

Además, Tessmann (1930) documenta, bajo el término < Nokamán>, una variedad lingüística pano que, tal como se demuestra en Zariquiey (en prensa) es un dialecto, probablemente extinto, de cashibo-cacataibo. Este dialecto podría corresponderse con un quinto grupo identificado por Winstrand bajo 
la denominación camano. En realidad, tal como se discute en Zariquiey (en prensa) el término <Nokamán $>$ podría haber sido una mala consignación del término camano.

El estudio más reciente sobre la dialectología del idioma se ofrece en Zariquiey (2011b). Si bien los resultados ofrecidos en ese estudio coinciden en gran medida con el análisis de Winstrand (1969), en Zariquiey (2011b) se ofrece por primera vez una descripción detallada y sistematizada de las correspondencias fonológicas que separan los distintos dialectos del cashibocacataibo y se listan brevemente, además, algunas diferencias léxicas y morfosintácticas entre los mismos. De acuerdo a los datos ofrecidos en Zariquiey (2011b), el idioma cashibo-cacataibo presenta actualmente cuatro variedades dialectales vivas: la del río San Alejandro, la del Bajo Aguaytía (que es la misma que la del Shamboyacu), la del Alto Aguaytía y la del río Sungaroyacu. Las tres últimas variedades presentan diferencias mínimas y podrían ser agrupadas en una sola rama, opuesta a la de San Alejandro, que representa la variedad más divergente del idioma. $\mathrm{El}<$ Nokamán> de Tessmann, tal como se demuestra en Zariquiey (en prensa), está más cercanamente emparentado con el dialecto de San Alejandro que con ningún otro. Es importante resaltar que los datos ofrecidos en Zariquiey (2011b), obtenidos a partir de la metodología comparativa tradicional, han sido corroborados por especialistas del Instituto Max Planck para la Antropología Evolutiva (MPI-EVA) mediante métodos más modernos. Así, a los 40 conceptos más estables en la lista de Swadesh (Holman et al. 2008) se les aplicó el proceso de "transcripción" (Brown et al. 2008) y la medida de distancia lexical (Wichmann et al. 2010) del programa ASJP, que ha sido especialmente diseñado para la medición de los patrones de separación dialectal a lo largo del tiempo. Los resultados obtenidos mediante el referido programa se corresponden exactamente con los resultados presentados en Zariquiey (2011b), que son resumidos a través del siguiente esquema, que incluye también la ubicación del <Nokamán >, tal y como fuera documentado por Günter Tessmann:

\section{Esquema 1. Dialectología cashibo-cacataibo}

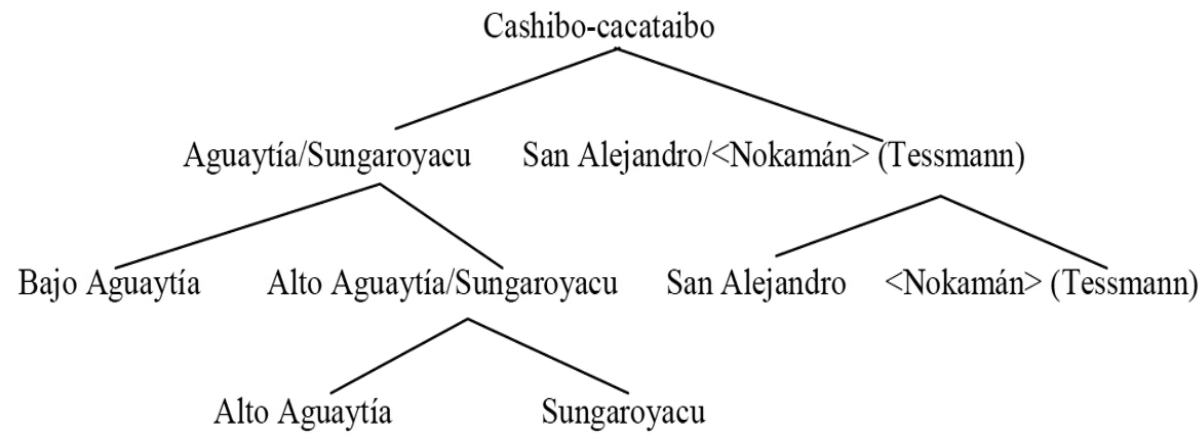




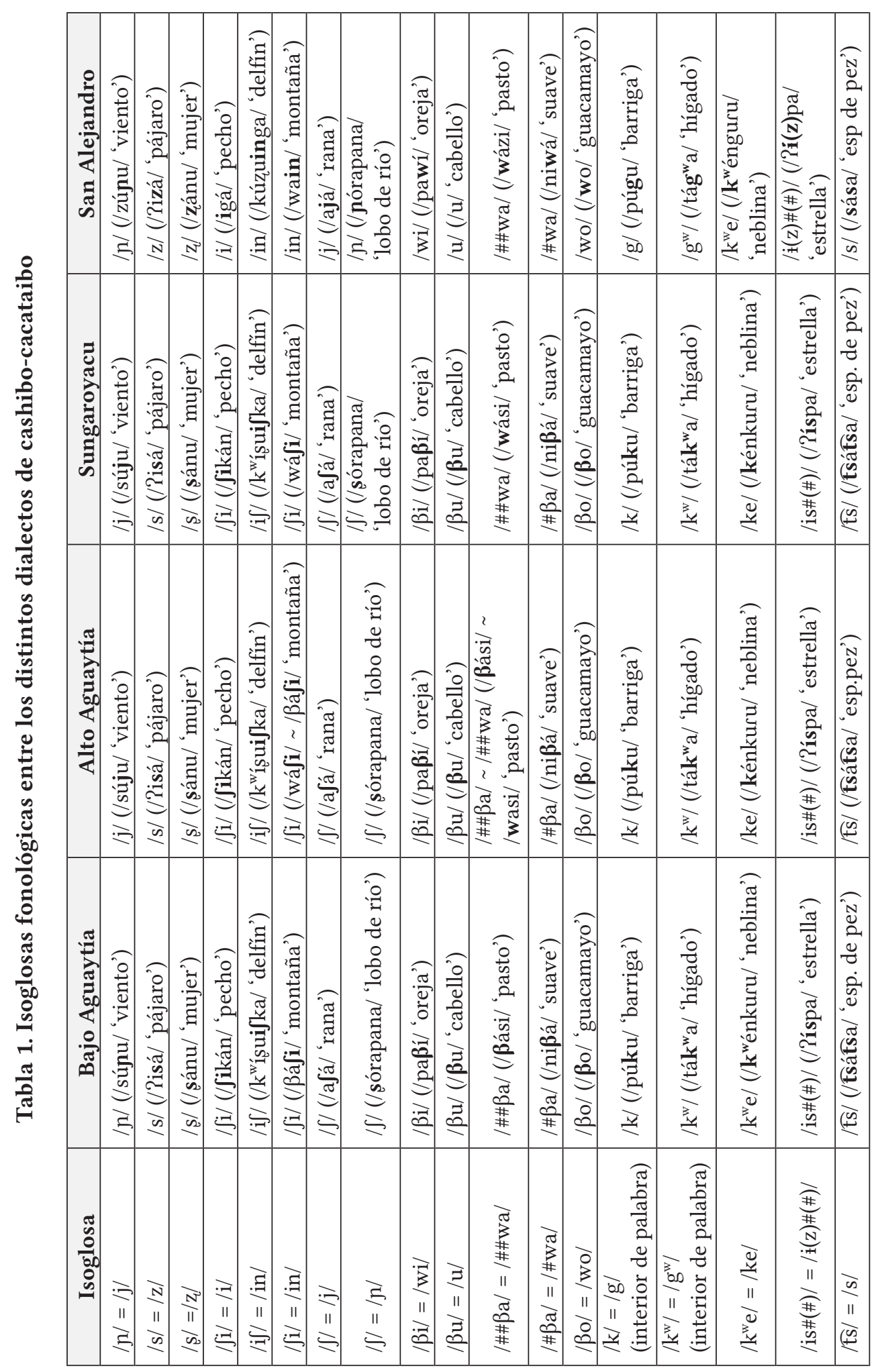


El esquema 1 ha sido elaborado a partir de distintos tipos de evidencia (desde fonológica hasta morfosintáctica). La tabla 1, por ejemplo, incluye las isoglosas fonológicas más importantes entre los distintos dialectos (todas ellas presentadas en Zariquiey 2011b), las mismas que muestran la particularidad del dialecto de San Alejandro. Asimismo, en la tabla 2 se incluyen algunas correspondencias léxicas entre los cuatro dialectos. Todas ellas señalan al dialecto de San Alejandro como el más divergente (tal como se indica también en Zariquiey 2011b, lo mismo ocurre con varios aspectos morfosintácticos).

\section{Tabla 2. Diferencias léxicas entre los cuatro dialectos de cashibo-cacataibo}

$\begin{array}{lllll}\text { /Ritsís/ } & \text { /Ritsís/ } & \text { /Ritsís/ } & \text { /zána/ } & \text { 'caliente' } \\ \text { /usín/ } & \text { /unsín/ } & \text { /unsín/ } & \text { /róza/ } & \text { 'rojo' } \\ \text { /maská/ } & \text { /maská/ } & \text { /maská/ } & \text { /mápuzo/ } & \text { 'cabeza humana' } \\ \text { /sáí/ } & \text { /sáí/ } & \text { /sáí/ } & \text { /tipa/ } & \text { 'especie de tortuga' } \\ \text { /saíon/ } & \text { /saíon/ } & \text { /saíon/ } & \text { /kaúri/ } & \text { 'especie de tortuga fluvial' } \\ \text { /sapín/ } & \text { /sapín/ } & \text { /sapín/ } & \text { /waxú/ } & \text { 'tela de araña' }\end{array}$

Como podemos apreciar, la realidad dialectological del cashibo-cacataibo es relativamente compleja. Esta diversidad dialectal puede tener su explicación en la historia de los hablantes y, particularmente, en su poco contacto con los misioneros franciscanos que se establecieron en el Ucayali durante los siglos XVIII y XIX. Estos misioneros construyeron la idea de que los "cashibos" eran fieros y salvajes y, por ello, asumieron que era sencillamente implosible crear misiones con ellos. De esta forma, los cashibo-cacataibo nunca vivieron con los misioneros franciscanos y evitaron, por tanto, la homogeinización cultural que la convivencia con ellos podía acarrear (homogeinización que se aprecia de manera muy clara en el caso de los shipibos, conibos y shetebos, que - por influencia de los franciscanos - se convirtieron en un solo pueblo: el shipiboconibo; Tournon 2002).

Los cashibo-cacataibo solo se contactaron más intensamente con el resto del país hacia 1930-1940, cuando, guiados por hombre de su propia etnia llamado Simón Bolívar Odicio, emprendieron el trazado de un tramo de la carretera Federico Basadre. Por este servicio al Estado Peruano, el Presidente Manuel Prado le concedió al pueblo cashibo-cacataibo una reserva territorial que forma parte de sus territorios actualmente reconocidos.

En lo que sigue, basándonos en la diversidad dialectológica actual que acabamos de presentar, ofreceremos un estudio lingüístico del $<$ Kaschibo $>$ de Tessmann (1930). Nuestro estudio prestará especial atención a las primeras 31 
entradas recogidas por el referido autor, ya que, para ellas, Tessmann consigna información para los tres sub-grupos que identifica: <Kaschinõ $>$, $<$ runõ $>$ y $<$ Kakataibo $>$. Sin embargo, información basada en el análisis de los 81 entradas restantes, que solo incluyen datos para $<$ Kaschinõ $>$, también es ofrecida y discutida en el presente artículo, ya que nos permitirá corrobar algunas de las ideas esbozadas a partir del estudio de las primeras 31 entradas.

\section{Los <Kaschibo $>$ de Tessmann (1930)}

En lo que sigue discutimos algunos de los aspectos más saltantes de los datos lingüísticos ofrecidos por Tesmann acerca del grupo que él documentó bajo el nombre $<$ Kaschibo $>$. Para las presentaciones ofrecidas en las secciones siguientes, hemos empleado tanto la versión alemana de 1930 como la española de 1999 (ver bibliografía). Esto se debe, básicamente, a las características propias de los materiales recién citados. Mientras que la traducción de 1999 facilita enormemente la consulta del texto original de Tessmann, el tratamiento de las listas léxicas en lenguas indígenas en la versión de 1999 deja mucho que desear: los signos empleados por Tessmann en el original de 1930 han sido radicalmente transformados y simplificados, y, por lo tanto, el empleo de la versión española para estudios lingüísticos como el emprendido aquí debe ser simplemente evitado bajo cualquier circunstancia.

\subsection{Localizacion y diversidad de los $<$ Kaschibo $>$ de Tessmann}

Günter Tessmann ofrece un amplio informe etnográfico sobre el pueblo $<$ Kaschibo $>$, lleno de datos sumamente interesantes. Este informe está compuesto de 75 tópicos etnográficos que ofrecen una descripción bastante completa del pueblo en cuestión. Se incluye información que va desde los nombres con que ha sido llamado en la literatura (entre los que el autor menciona Manamabobo, Mananagua y Carapacho, entre otros) hasta sus prácticas culturales (vestimenta, vivienda, alimentación, etc.) y económicas (caza, pesca, agricultura, etc.), pasando por su religión, su mitología y creencias, etc. Por razones de espacio, no ofreceremos mayores detalles sobre estos aspectos, pero invitamos al lector interesado a revisar el trabajo de Tessmann para referencias más específicas. En lo que sigue, nos avocaremos únicamente a describir la localización que Tessmann atribuye a este pueblo y los distintos clanes que lista.

Tessmann (1930:127) ofrece una descripción del territorio tradicional y actual de los <Kaschibo $>$, el cual se ubica, según el autor, entre los ríos Pachitea y Cushabatay, entre la cordillera del Huallaga hacia la orilla derecha y el Ucayali. En relación a ello, Tessmann explica que el centro del territorio del pueblo era el Aguaytía superior. Aunque el autor indica explícitamente que los $<$ Kaschibo $>$ no ocupan todos los ríos incluidos en el territorio especificado, 
es claro que se trata de un territorio relativamente amplio. Asimismo, se nos ofrece una detallada información acerca de los clanes o secciones $<$ Kaschibo $>$, los mismos que, según Tessmann, se pueden clasificar en tres grupos, tal como es detallado en la tabla siguiente (que incluye las etimologias dadas por el propio Tessmann):

Tabla 3. La clasificación de Tessmann de los clanes $<$ Kaschibo $>$

\section{Grupo $<$ Kaschinõ $>$}

1. kašinõ

2. rūinõ

3. warínõ

4. tšažonǒ

5. naibo

6. naítabohuni de kaši = murciélago, por lo tanto, gente del murciélago

de rui $=$ taro, por lo tanto, gente del taro

de warí = sol, por lo tanto, gente del sol

de tšažo = venado paletero, por lo tanto, gente del venado

de nai $=$ mono perezoso, bo $=$ multitud, pueblo, por lo tanto, pueblo del mono perezoso

de naítabo $=$ Ara macao y huni $=$ hombres, por lo tanto, hombres del Arara

\section{Grupo $<$ Runõ $>$}

7. rōunõ

8. winanõ

9. aínõ

10. šokenõ

11. inonõ

12. širinõ

13. tonánõ

14. hunínõ de rōu = mono aullador, por lo tanto, gente del mono aullador

de wina $=$ avispa, por lo tanto, gente de la avispa

de aí = mujer, por lo tanto, gente de la mujer

de šoke = tucán pequeño, Arassari, por lo tanto, gente del Arassari

de ino $=$ tigre, por lo tanto, gente del tigre

de širi = trogon (?), por lo tanto, gente del trogon (?) de toná $=$ negro, por lo tanto, gente negra (por la piel morena de los integrantes de este clan) from huni $=$ ser humano, hombre, por lo tanto, los hombre

15. kamaigohunide kamaigo = una clase de iguana, por lo tanto, gente de la iguana

16. tsalgūnõ de tsalgū = Polla de agua (punchana L), por lo tanto, gente de la polla de agua

17. buniño de buni $=$ una clase de árbol

\section{Grupo $<$ Kakataibo $>$ :}

18. <Kakataibo> no se me pudo explicar, debería significar algo como "buena gente" 
Si bien en la actualidad los miembros del pueblo cashibo-cacataibo que hemos tenido oportunidad de entrevistar no reconocen varios de estos nombres, los datos ofrecidos por Tessmann y presentados en la tabla 3 suscitan un gran interés por su aparente heterogeneidad. El propio Tessmann se encarga de señalar que lingüísticamente los grupos que él identifica son bastante similares entre sí (con excepción de los < Kakataibo > que son, según él, los más divergentes en términos lingüísticos). Lamentablemente, si bien el autor da una referencia geográfica general para el pueblo, no hace lo propio con cada uno de los subgrupos, por lo que es difícil interpretar los materiales lingüísticos que presenta en relación a los grupos cashibo-cacataibo contemporáneos (ver §5.1).

\subsection{El corpus lingüístico del $<$ Kaschibo $>$ de Tessmann}

Además de las más de cincuenta palabras <Kaschibo > que aparecen en el cuerpo del texto etnográfico (que dejamos de lado en esta oportunidad, debido a la dificultad extra que plantean -ni siquiera es posible saber a qué dialecto pertenecen-), Günter Tessmann ofrece una lista léxica con un total de 112 palabras < Kaschibo > al final de la nota etnográfica que preparó sobre este pueblo. Las primeras 31 (que corresponden a las 33 entradas de la lista básica elaborada por Tessmann menos las palabras para 'tabaco' y 'canoa' que Tessmann indica como inexistentes en $<$ Kaschibo $>$ ) incluyen información acerca de los tres dialectos que el autor identifica: $<$ Kaschinõ $>,<$ Runõ $>$ y $<$ Kakataibo $>$. Para las 81 palabras restantes, el etnógrafo alemán solo consigna información para el dialecto que él denomina $<$ Kaschinõ $>$.

Las primeras 31 palabras son muy importantes para el estudio que presentaremos en el presente artículo, ya que nos permiten comparar los dialectos documentados por Tessmann con los dialectos actuales del idioma cashibo-cacataibo. Este trabajo se complementará con el estudio de las 81 palabras restantes, las que nos permitirán hacernos una idea más clara de las características más saltantes del dialecto $<$ Kaschinõ $>$. Para ello, prestaremos atención a aspectos tanto léxicos como fonológicos (que puedan postularse a partir de una interpretación filológica del original alemán). En el camino, tal como veremos, surgirán interesantes pistas que nos permitirán, además, trazar algunos procesos de cambio lingüístico altamente relevantes para comprender un poco mejor la historia del idioma cashibo-cacataibo.

\section{Análisis de los datos de $<$ Kaschibo $>$ de Tessmann}

En lo que sigue presentamos nuestro estudio de los datos de $<$ Kaschibo $>$ ofrecidos por Günter Tessmann en su libro de 1930. Para ello, hemos dividido nuestra exposición en dos partes. En la primera, nos avocaremos al análisis de 
los datos ofrecidos por Tessmann para las primeras 31 entradas léxicas de su lista; mientras que en la segunda, presentaremos el análisis de los 81 lexemas restantes. En ambos casos, nuestro análisis parte de la comparación de los datos de Tessmann con datos recogidos por nosotros en el campo para los cuatro dialectos actuales del idioma cashibo-cacataibo. La metodología empleada en la comparación es bastante sencilla y ha sido respetada de manera rigurosa. El principio básico ha sido tratar de evitar cualquier sobreinterpretación en torno a los datos de Tessmann. Por ello, si Tessmann ofrece una palabra para un determinado concepto que no se corresponde a lo que encontramos en los dialectos contemporáneos de cashibo-cacataibo, ello se contabiliza siempre como una diferencia léxica, aunque el dato de Tessmann corresponda a una palabra cashibo-cacataibo contemporánea correspondiente a un concepto semánticamente relacionado. Así, por ejemplo, para la palabra 143, Tessmann da la forma <njorobana > para 'nutria', significado que corresponde a la palabra /ßúnsime/ en los dialectos contemporáneos de cashibo-cacataibo. Ahora bien, en dichos dialectos la forma /Jórapana/ /nórapana/ sí existe y refiere al 'lobo de río'. Entonces, si bien sería posible contar < njorobana> como un cognado con /sórapana/ /nórapana/, preferimos no hacerlo, ya que podríamos estar sobreinterpretando el dato de Tessmann: es una posibilidad también plausible que el referente de $<$ njorobana $>$ en el $<$ Kaschinõ $>$ haya sido el referente de /ßúnsime/ en los dialectos actuales, debido a un cambio semántico de alguna índole. Otro ejemplo similar aparece en la entrada 16, 'persona', para la cual el autor consignó la forma $<$ nõ $>$ para uno de los dialectos de $<$ Kaschibo $>$. La palabra para 'persona' en los dialectos contemporáneos de cashibo-cacataibo es /uni/, pero todos estos dialectos presentan la forma /no/ para 'extranjero o enemigo'. En este caso, tampoco hemos realizado ningún tipo de interpretación adicional sobre el dato de Tessmann y no hemos consignado este caso como correspondencia. Tal como podemos apreciar, el objetivo ha sido siempre respetar lo consignado por Tessmann de manera rigurosa, aunque sepamos que la palabra consignada por el autor existe en los dialectos contemporáneos con un significado similar.

Este principio se ha aplicado sistemáticamente a lo largo del corpus, aunque en tres entradas (47, 217 y 218), que incluyen formas morfológicamente complejas, hemos tenido que ser más flexibles. Si bien las entradas no parecen cognados en una primera mirada, los formativos $/ \mathrm{ka} /, / \mathrm{kwi} / \mathrm{y} / \mathrm{mi} /$ significan respectivamente 'espalda', 'derecha' e 'izquierda' y aparecen tanto en los dialectos sincrónicos de cashibo-cacataibo como en el $<$ Kaschinõ > de Tessmann. Por tanto, en esos casos, hemos tenido a bien considerar las entradas como cognados (una discusión más detallada de estos principios metodológicos se ofrece en Zariquiey en prensa con relación a los datos de Tessmann sobre $<$ Nokamán>). Finalmente, nótese que hemos contado como coincidencia léxica 
también aquellos casos en los que la correspondencia se establece con una palabra existente pero no favorita en un dialecto determinado. Esto ocurre, por ejemplo, con la entrada 19, 'perro', que tiene dos formas léxicas asociadas, /Putitji/ y /kamún/, ambas documentadas por Tessmann.

Con relación a los temas fonológicos, debemos decir que la interpretación filológica de materiales como los de Tessmann es sumamente compleja. En ese sentido, el presente artículo no pretende constituirse en una discusión detallada de los problemas de interpretación filológica de los datos de Tessmann. Por el contrario, nos hemos avocado básicamente a aquellos puntos que tienen una interpretación filológica más o menos transparente (otra vez, Cf. Zariquiey en prensa para un ejemplo de interpretación filológica más detallada de los datos de Tessmann sobre < Nokamán>).

\subsection{Palabras numeradas del 1 al 33 en la lista de Tessmann}

La tabla 4 presenta los datos a discutir en esta sección, incluyendo tanto los datos de Tessmann como los obtenidos por nosotros en el campo. El símbolo “ऍ” fue empleado por el autor alemán para indicar aquellos casos en los que alguno de los otros dialectos no mostraba ninguna diferencia, ni fonológica ni léxica, en relación al dialecto a la izquierda (si encontramos el símbolo “๘” repetido, estamos ante casos en los que no se encuentra divergencia alguna entre los tres dialectos documentados por Tessmann). Nótese, además, que, tal como ya se mencionó, de las 33 palabras incluidas en la lista básica, Tessmann indica que dos no poseen un correlato en los dialectos de $<$ Kaschibo $>$ (15 'canoa' y 27 'tabaco').

En un total de 13 casos, los tres dialectos documentados por Tessmann no muestran divergencia alguna, ni léxica ni fonológica (incluimos en este número, los casos 22 y 23, para los que Tessmann no empleó el símbolo “ऍ”, a pesar de no existir prácticamente ninguna divergencia entre los dialectos). Tales casos no son relevantes para el análisis ofrecido aquí, ya que no nos permiten establecer relaciones entre los dialectos documentados por el autor alemán y los dialectos actuales de cashibo-cacataibo. Sin embargo, pueden ser interesantes ya que sugieren que los tres dialectos de $<$ Kaschibo $>$ documentados por Tessmann tenían un grado considerable de similitud. Finalmente, para una de las palabras de la lista, no se encuentra correspondiente en ninguno de los dialectos actuales de cashibo-cacataibo (30). ${ }^{3}$ Al dejar de lado esas entradas, nos quedamos con un total de 16 palabras, presentadas en la tabla 5. Estas palabras serán el centro de nuestra discusión:

3 Nótese que las formas que da Tessmann no significan en ningún caso 'tres'. La forma <mökoóntapo> significa más bien algo como 'mano completa'; mientras que <ídza> significa 'mucho'. 


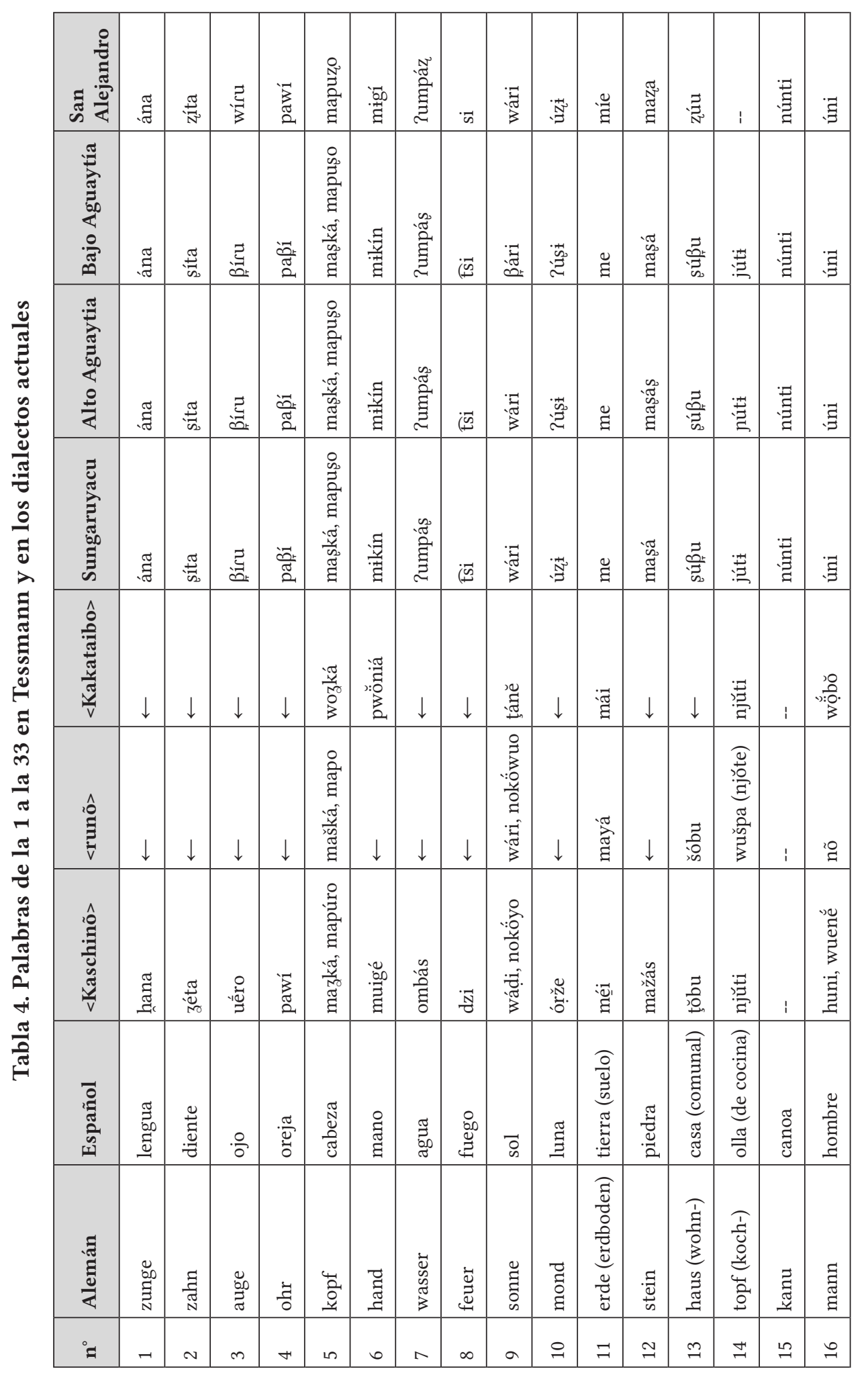




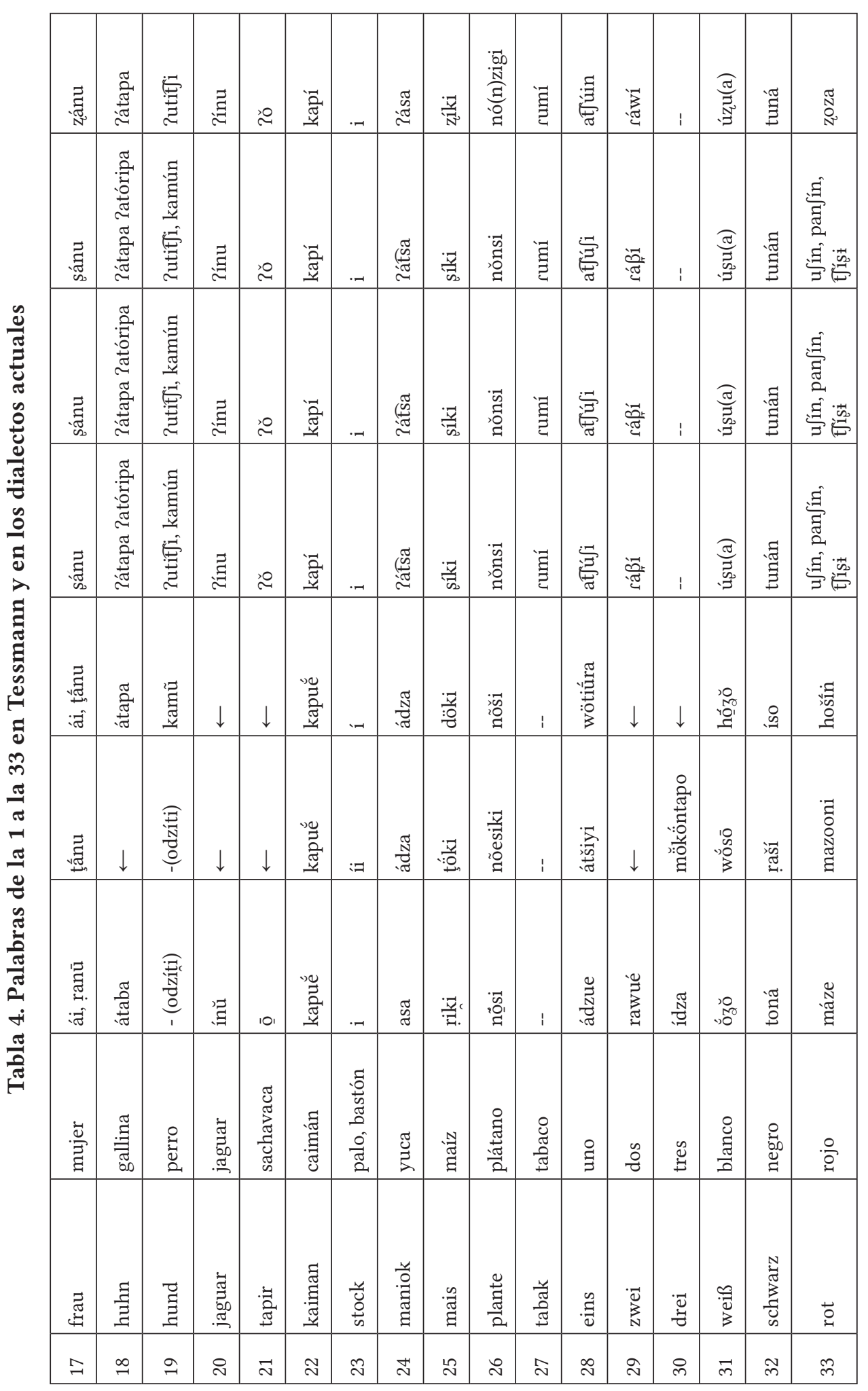




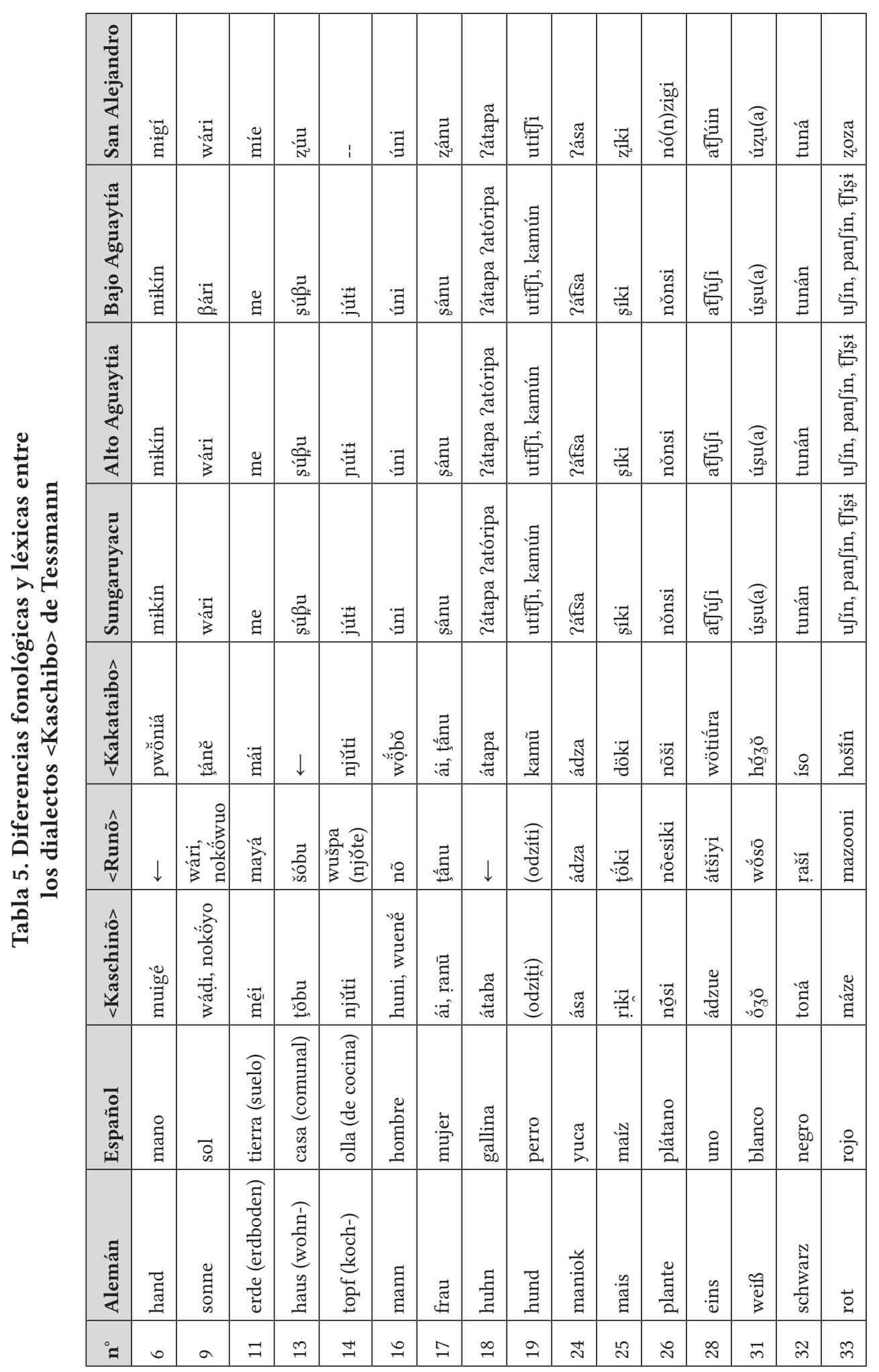




\subsubsection{Aspectos léxicos}

Empecemos por estudiar las diferencias léxicas entre los dialectos documentados por Tessmann, con la finalidad de explorar si es posible asociarlos con los dialectos actuales del idioma. Tal como veremos, los datos son altamente imprecisos en este sentido y, por lo tanto, no arrojan conclusiones contundentes. La tabla 6 presenta solo los casos que muestran diferencias léxicas para su discusión posterior.

En 6 ('mano') y 9 ('sol'), el dialecto <Kakataibo> no es solo divergente con relación a los otros dialectos de Tessmann, si no también a los dialectos de cashibo-cacataibo contemporáneos y este hecho es sumamente llamativo. Sin embargo, es difícil postular un juicio definitivo sobre este punto, ya que <pwöniá> parece ser cognado con la forma contemporánea/pinan/ que significa 'brazo' y no 'mano'; mientras que <ţánĕ> parece ser cognado con la forma contemporánea /sana/ que significa 'caliente' y no 'sol'. Siempre será difícil determinar si estamos ante un error de consignación por parte de Tessmann o ante una diferencia semántica realmente existente en el momento en que Tessmann documentó los dialectos. Algo similar ocurre en 33 ('rojo'), en donde son las formas asignadas a los dialectos $<$ Kaschinõ $>$ y $<$ runõ $>$ las que podrían estar revelando un error de consignación: las palabras $<$ máze $>$ y $<$ mazooni> están relacionadas al término /masii/ 'achiote', que es una planta con fruto de color rojo, pero no significan 'rojo'. Sin embargo, en este caso el dato de <Kakataibo $>$ se corresponde con lo encontrado en tres de los cuatro dialectos contemporáneos de cashibo-cacataibo (el dialecto divergente es el de San Alejandro) y, por lo tanto, el caso de 33 es un tanto distinto. Tal como hemos comentado, estos casos no permiten afirmar nada de manera contundente.

Sin embargo, la presencia del término <ţánĕ> (9) en <Kakataibo > sí es relevadora en otro sentido y muestra lo que podría ser una particularidad de este dialecto: más allá de que haya significado o no 'sol', tal como se ha discutido arriba, <ţánĕ> podría ser un préstamo del shipibo-conibo. Esto es significativo, ya que el <Kakataibo $>$ de Tessmann presenta varios otros casos de préstamos similares: <wộ́bŏ> para 'hombre' (16); <wötiúra> para 'uno' (28) y, posiblemente, $<$ íso $>$ para 'negro' $(32){ }^{4}$

Los casos de préstamos separan al $<$ Kakataibo $>$ no solo de los otros dialectos documentados por Tessmann, sino también de los dialectos contemporáneos de cashibo-cacataibo. Y esto incluye al dialecto del río San Alejandro, que es conocido como cacataibo desde, por lo menos, Winstrand (1969). Hubiese sido esperable encontrar una correspondencia léxica entre el cacataibo de

4 Sin embargo, esta no es la situación encontrada en (19), ya que la forma /kamún/ para 'perro' parece ser un término propio del cashibo-cacataibo, mientras que / $u$ utitfi/ es muy probablemente un término prestado del shipibo-conibo. 


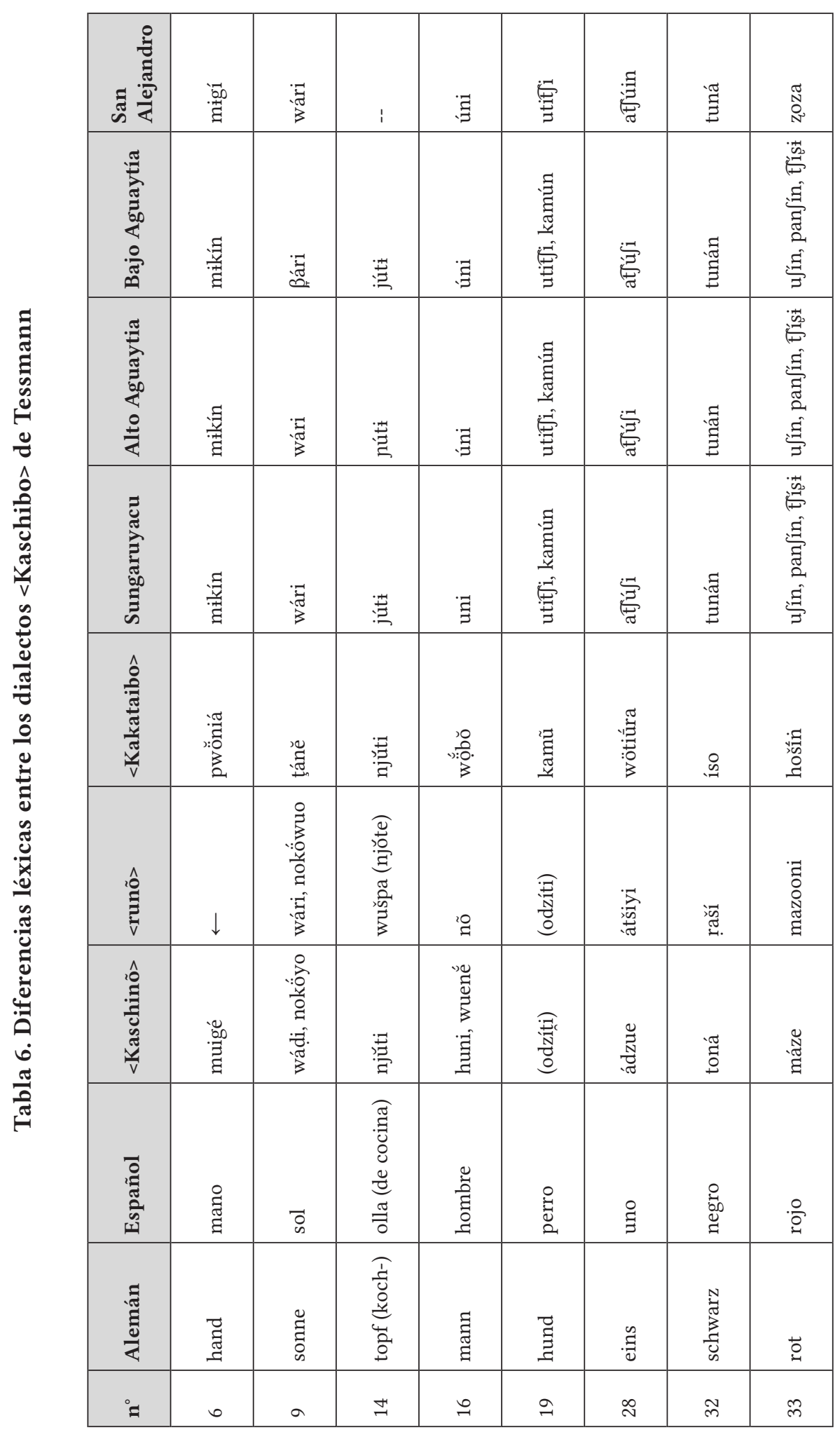

Volume 5, Número 1, Julho de 2013177 
San Alejandro y el <Kakataibo > de Tessmann; pero, desafortunadamente, este patrón no se revela en los datos. Todo lo contrario, casos como 19 'perro' y 33 'rojo', en donde el <Kakataibo> de Tessmann presenta dos formas propiamente cashibo-cacataibo que crucialmente ya no existen en el dialecto de San Alejandro actual, apuntan a una diferenciación entre ambas variedades. Este es un dato novedoso, ya que deja en claro que no contamos con evidencia lingüística sólida para afirmar que el $<$ Kakataibo $>$ de Tessmann, el dialecto más divergente en su muestra, represente un estadío anterior del dialecto de San Alejandro, que no solo ha recibido el mismo nombre, sino que, además, es el dialecto contempóraneo más divergente. El hecho de que ambos dialectos hayan sido nombrados de la misma forma es significativo y podría sugerir la asociación $<$ Kakataibo $>$ de Tessmann $=$ dialecto de San Alejandro (sobre todo cuando tomamos en cuenta que en ambos casos estamos ante dialectos altamente divergentes; sin embargo, este estudio de los datos de Tessmann muestra que, en realidad, tal afirmación no tiene asidero lingüístico.

De forma similar, tal como una rápida evaluación de los datos en la tabla 7 revela, no es posible establecer tampoco una relación convincente entre los dialectos $<$ Kaschinõ $>$ y $<$ Runõ $>$ de Tessmann y cualquiera de los otros dialectos contemporáneos de cashibo-cacataibo. Winstrand (1969) da el término rubo como correspondiente al grupo del Alto Aguaytía y, en ese sentido, uno podría sentirse inclinado a atribuirle el mismo valor al término $<$ Runõ $>$ de Tessmann. Sin embargo, otra vez, no contamos con ninguna evidencia lingüística para tal asociación. No es posible establecer ninguna asociación sólida a partir de datos léxicos entre los dialectos de Tessmann y los dialectos contemporáneos de cashibo-cacataibo. Esto se deja ver en la siguiente tabla, en la que se ofrecen los resultados de la comparación léxica entre los dialectos de Tessmann y los dialectos contemporáneos. El número incluido en cada casillero corresponde al número de coincidencias léxicas entre dialectos a partir del universo de 16 palabras, referido más arriba.

Varios datos son reveladores en esta tabla. El primero es que, tal como lo mencionamos arriba, la relación más débil es la encontrada entre los dialectos $<$ Kakataibo $>$ y San Alejandro, a pesar de que ambos dialectos han recibido el mismo nombre en la literatura. Lo segundo es que, en general, el <Kakataibo > es el dialecto de Tessmann más divergente en relación a los dialectos contemporáneos. Finalmente, es importante mencionar que el $<$ Kashinõ $>$ de Tessmann es el dialecto más similar a los dialectos contemporáneo de cashibocacataibo.

\subsubsection{Aspectos fonológicos}

La evidencia fonológica no es demasiado clara, pero, sin embargo, no deja de ser interesante. Tal como veremos, el estudio de los datos de Tessmann sugiere 
Tabla 7. Número de correspondencias léxicas entre los dialectos < Kaschibo> de Tessmann y los dialectos contemporáneos de cashibo-cacataibo

\begin{tabular}{|l|c|c|c|c|}
\hline & Sungaroyacu & Alto Aguaytía & Bajo Aguaytía & San Alejandro \\
\hline$<$ Kashinõ $>$ & 15 & 15 & 15 & 14 \\
\hline$<$ runõ $>$ & 13 & 13 & 13 & 12 \\
\hline$<$ Kakataibo $>$ & 11 & 11 & 11 & 8 \\
\hline
\end{tabular}

una correspondencia fonológica inesperada entre el dialecto $<$ Kaschinõ $>$ de Tessmann y el dialecto contemporáneo de San Alejandro. Empecemos por los ejemplos en 24 'yuca' y 28 'uno' (en la tabla 5). Tal como se aprecia en la tabla 6, la forma para 'yuca' en <Kaschinõ > es <asa $>$ y, por tanto, no presenta la africada /ts/ reconstruible para esa palabra (*/átsa/). Esto podría revelar un proceso de deafricación que solo se encuentra en el dialecto de San Alejandro, tal como se aprecia en los datos correspondientes en la tabla 6. En esa misma línea, encontramos que la forma para 'uno' en el <Kaschinõ > de Tessmann, <ádzue>, se parece más a la forma encontrada en San Alejandro, /atjúin/ que a la forma encontrada en los dialectos restantes: /atfúfi/. Algo similar, pero un tanto más incierto, podría afirmarse para 32, en donde la forma sin nasal para la palabra 'negro' < toná> en el dialecto $<$ Kaschinõ $>$ se parece más a la que se documenta para San Alejandro. ${ }^{5}$

Esta relación - totalmente inesperada - entre el dialecto de San Alejandro y el <Kaschinõ > es el único dato más o menos sistemático que puede obtenerse de los datos de Tessmann. Sin embargo, ya hemos mencionado en la nota 4 que, por lo menos en un caso, es el dialecto $<$ Runõ $>$ de Tessmann el que se parece al de San Alejandro. En este contexto, tal como se reveló a partir de la comparación léxica, es importante mencionar que el dialecto de San Alejandro y el <Kakataibo $>$ de Tessmann son los que menos se parecen entre sí. Si bien Tessmann no especifica la localización de cada uno de los grupos, lo que se habría esperado es que el dialecto contemporáneo de San Alejandro guardara una semejanza más significativa con el $<$ Kakataibo $>$ de Tessmann, debido a que, tal como se explicó, este ha recibido tradicionalmente el mismo nombre en la literatura. Este patrón no se revela ni en los datos léxicos ni en los fonológicos y esto abre importantes preguntas acerca de aquello que documentó y encontró Tessmann, y acerca de los procesos de cambio lingüístico y reconfiguración dialectal por los que podría haber atravesado posteriormente el idioma cashibo-cacataibo. ${ }^{6}$

5 Sin embargo, la forma para 'plátano' (26) que encontramos en el < Runõ > de Tessmann presenta tres sílabas, tal como ocurre solo en el dialecto de San Alejandro contemporáneo. 6 No olvidemos que Tessmann se contactó con los cashibo-cacataibo justo antes de que 
Más allá de los problemas para explicar la dialectología del idioma, la lista de Tessmann sí ofrece algunos datos contundentes que colaboran directamente con la compresión de los procesos de cambio fonológico en el cashibocacataibo. El primer dato relevante es que las transcripciones ortográficas del autor indican que, cuando Tessmann documentó los distintos dialectos de $<$ Kaschibo $>$, estos presentaban un sonido aspirado glotal /h/ que no existe actualmente en ningún dialecto contemporáneo del idioma. Esto se aprecia claramente en las palabras para 'lengua' (1), transcrita como < hana $>$ y para 'persona' (16), que es <huni $>$ para el dialecto $<$ Kaschinõ $>$. Este es un hecho sumamente relevante, ya que, tal como se explica en Zariquiey (2011a: cap. 2), la ausencia de /h/, en combinación con la presencia de una oclusiva glotal / / distintiva, es una de las características fonológicas más llamativas del idioma cashibo-cacataibo contemporáneo. Tal como se detalla en el referido trabajo, la situación actual de la glotalización en cashibo-cacataibo podría explicarse a partir de la pérdida de la fricativa glotal a inicio de palabra y los datos ofrecidos por Tessmann no hacen sino reforzar tal hipótesis: el cashibo-cacataibo tuvó /h/ hacia 1920.

Por otro lado, los datos sobre la correspondencia entre / $\mathrm{n} / \mathrm{y} / \mathrm{j} /$ entre los distintos dialectos de cashibo-cacataibo son sumamente interesantes: tal como se aprecia en la tabla 1, mientras que los dialectos de San Alejandro y Bajo Aguaytía presentan la nasal palatal, los del Alto Aguaytía y de Sungaroyacu presentan la aproximante palatal. Ahora bien, a partir de ejemplos como el de la palabra 14 de la lista de Tessmann, se podría concluir que cuando el etnógrafo alemán documentó el idioma <Kaschibo>, todos sus dialectos presentaban el sonido $/ \mathrm{n} /$. Esto es importante porque este sonido nasal parece haber sido una innovación de ciertos dialectos de cashibo-cacataibo al interior de la familia lingüística pano. Lo que sugieren los datos de Tessmann es que, en realidad, esta innovación podría haber sido previa a la dispersión de los distintos dialectos del idioma. Una vez diversificados, dos de estos dialectos altamente emparentados entre sí - (Sungaroyacu y Alto Aguaytía) se habrían vuelto "conservadores" otra vez, muy probablemente por contacto con shipibo-conibo, al incorporar nuevamente la / $\mathrm{j} /$ en sus inventarios fonológicos (Sungaroyacu y Alto Aguaytía). Pero esto habría ocurrido posteriormente a la visita de Tessmann.

Otro dato sumamente interesante tiene que ver con las monoptongaciones: /aj(a)/ > /e/ y /aw(a)/ > /o/, rasgos también característicos de los diversos dialectos contemporáneos de cashibo-cacataibo (Zariquiey 2011a: cap. 2). Tal como lo revelan los datos de Tessmann, tales procesos de monoptongación muestran una cronología relativa muy clara, según la cual el cambio /awa/ >

Simón Bolívar Odicio agrupara a los cashibo-cacataibo y los hiciera vivir y trabajar juntos por largas temporadas (Gray 1953); Winstrand 1969). 
/o/ es anterior al cambio /ai(a)/ > /e/. Eso se aprecia con claridad al comparar las palabras en 11 y 21. Mientras que la forma para 'tapir' en 21 es ya $<\overline{\underline{o}}>$ en los tres dialectos documentados por Tessmann, la forma para 'tierra' en 11 revela una alta variabilidad. La forma para 'tierra' ya ha sido monoptongada a algo como $/ \mathrm{me} /$ en los dialectos actuales (con la excepción del caso del dialecto de San Alejandro que parece ser irregular); sin embargo, los dialectos documentados por Tessmann revelan distintas situaciones con relación a este cambio: el < runõ > de Tessmann presenta la forma (más conservadora) < mayá>; el $<$ Kakataibo $>$ ofrece la forma reducida $<$ mái $>$; y el $<$ Kaschinõ $>$ presenta la forma $<$ mei $>$, en la que la calidad de la vocal inicial ya ha cambiado hacia algo parecido a una /e/ pero todavía se escucha una /i/ final. Este estadío podría ser el antecesor más inmediato de la forma contemporánea de la palabra en la mayoría de dialectos: /me/.

Estos son algunos de los datos que pueden extraerse del corpus elaborado por Tessmann y todos ellos son sumamente valiosos. En la sección que sigue exploraremos los datos restantes de su lista, que únicamente dan información acerca del dialecto <Kaschinõ $>$, y trataremos de determinar si es posible asociar este dialecto con alguno de los dialectos vivos de cashibo-cacataibo. Básicamente, nuestra pregunta será si en los datos que restan, esta inesperada relación entre el $<$ Kaschinõ $>$ de Tessmann, la variedad mejor documentada por el etnógrafo alemán, y el dialecto contemporáneo de San Alejandro se ve reforzada o invalidada.

\subsection{Palabras numeradas del 34 al 233 en la lista de Tessmann}

\subsubsection{Aspectos léxicos}

En esta sección ofrecemos un estudio de los datos que Tessmann incluyó en sus entradas léxicas entre la 34 y la 233, que solo dan información sobre el $<$ Kaschinõ $>$. Tessmann no fue particularmente riguroso en la compilación de estas entradas y del total de 199 entradas que hubiésemos encontrado si Tessmann hubiese recogido las correspondencias en $<$ Kaschinõ $>$ para todas las palabras alemanas enumeradas entre 34 y 233 en su lista, el autor da solo un total de 81 términos. En esta sección, ofrecemos una breve evaluación léxica y fonológica de estas 81 palabras con la finalidad de intentar establecer una relación entre el <Kaschinõ > y alguno de los dialectos actuales de cashibo-cacataibo, particularmente, el de San Alejandro. La tabla 8 presenta la lista completa de estas 81 palabras. Se incluye en la lista, además, los correspondientes de esas 81 palabras en los cuatro dialectos contemporáneos de cashibo-cacataibo:

Tal como se muestra en la tabla siguiente, los grados de similitud son prácticamente idénticos cuando comparamos el $<$ Kaschinõ > con los distintos dialectos contemporáneos. 
Tabla 9. Número de correspondencias léxicas entre el $<$ Kaschinõ $>$ de Tessmann y los dialectos contemporáneos de cashibo-cacataibo

\begin{tabular}{|c|c|c|c|c|}
\hline & Sungaroyacu & $\begin{array}{c}\text { Alto } \\
\text { Aguaytía }\end{array}$ & $\begin{array}{c}\text { Bajo } \\
\text { Aguaytía }\end{array}$ & $\begin{array}{c}\text { San } \\
\text { Alejandro }\end{array}$ \\
\hline $\begin{array}{c}\text { < Kaschinõ }> \\
\text { (Tessmann) }\end{array}$ & 52 & 52 & 52 & 53 \\
\hline
\end{tabular}

Tal como podemos apreciar, el dialecto de San Alejandro presenta una ligera diferencia con relación a los demás dialectos. Esta diferencia tiene que ver con la entrada 173, 'tortuga fluvial' que es <kawōli $>$ en $<$ Kaschinõ $>$ y /kauri/ en San Alejandro; mientras que en los dialectos restantes es /saíon/. Este dato, aunque no es suficientemente significativo (se trata de una sola palabra), apunta en la misma dirección sugerida por los datos discutidos en la sección anterior: el <Kaschinõ > de Tessmann se parece un poco más al dialecto de San Alejandro que a cualquier otro dialecto sincrónico de cashibo-cacataibo. Sorpresivamente, la evidencia fonológica a ser presentada a continuación apunta también en esa dirección, confirmando de manera prácticamente definitiva la relación encontrada hasta este punto.

\subsubsection{Aspectos fonológicos}

En la tabla 10 agrupamos 11 entradas previamente incluidas en la tabla 9 para su discusión en esta sección.

En las entradas 39 y 114, Tessmann hace uso del grafema $<$ l $>$. Tomando en cuenta que es prácticamente imposible que el $<$ Kaschinõ $>$ haya tenido un fonema o alófono lateral de tales características, ¿a que podría deberse su empleo para consignar sonidos que en los dialectos contemporáneos corresponden a elementos fricativos? Si bien la interpretación de esta decisión ortográfica no carece de dificultades, una explicación plausible es que el autor haya intentado consignar sonidos sonoros $(/ \mathrm{z} / \mathrm{y} / \mathrm{z} /$, como los que encontramos en San Alejandro) y no sonidos sordos (/s/ y /s/, como los que encontramos en el resto de dialectos). Aunque tal interpretación no deja de ser dudosa, si fuera correcta acercaría una vez más el < Kaschinõ > de Tessmann al dialecto de San Alejandro.

Asimismo, otra de las características del dialecto de San Alejandro es que exhibe simplemente $/ \mathrm{u} /$ en donde el resto de dialectos presenta $/ \beta \mathrm{u} /$ (ver tabla 1; Zariquiey 2011b). Esto parece apreciarse también en el dialecto $<$ Kaschinõ $>$ de Tessmann (cf., por ejemplo, 72, donde Tessmann no consigna ningún grafema para representar una aproximante bilabial). En esa misma línea, es importante mencionar otra característica distintiva del dialecto 


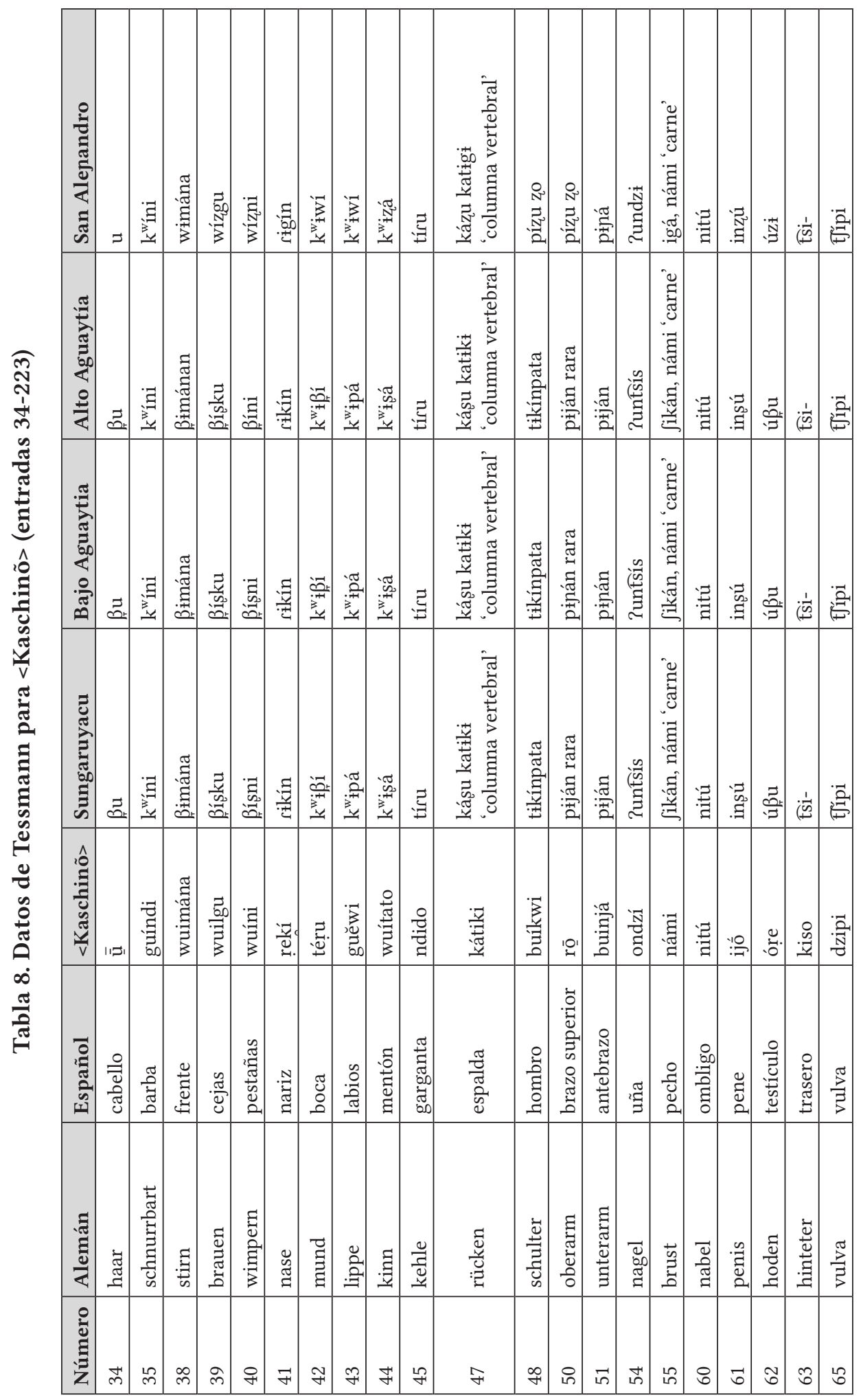




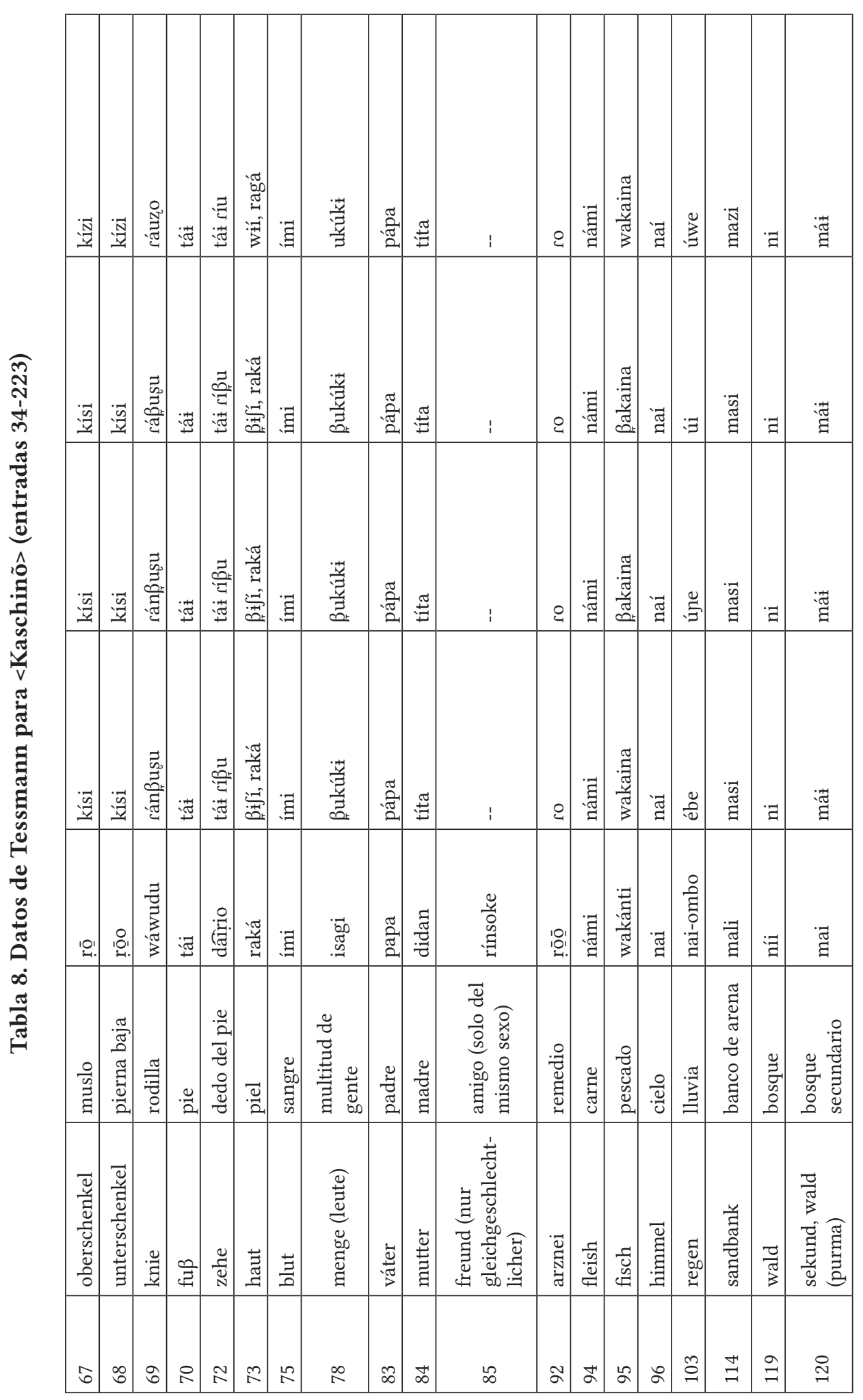




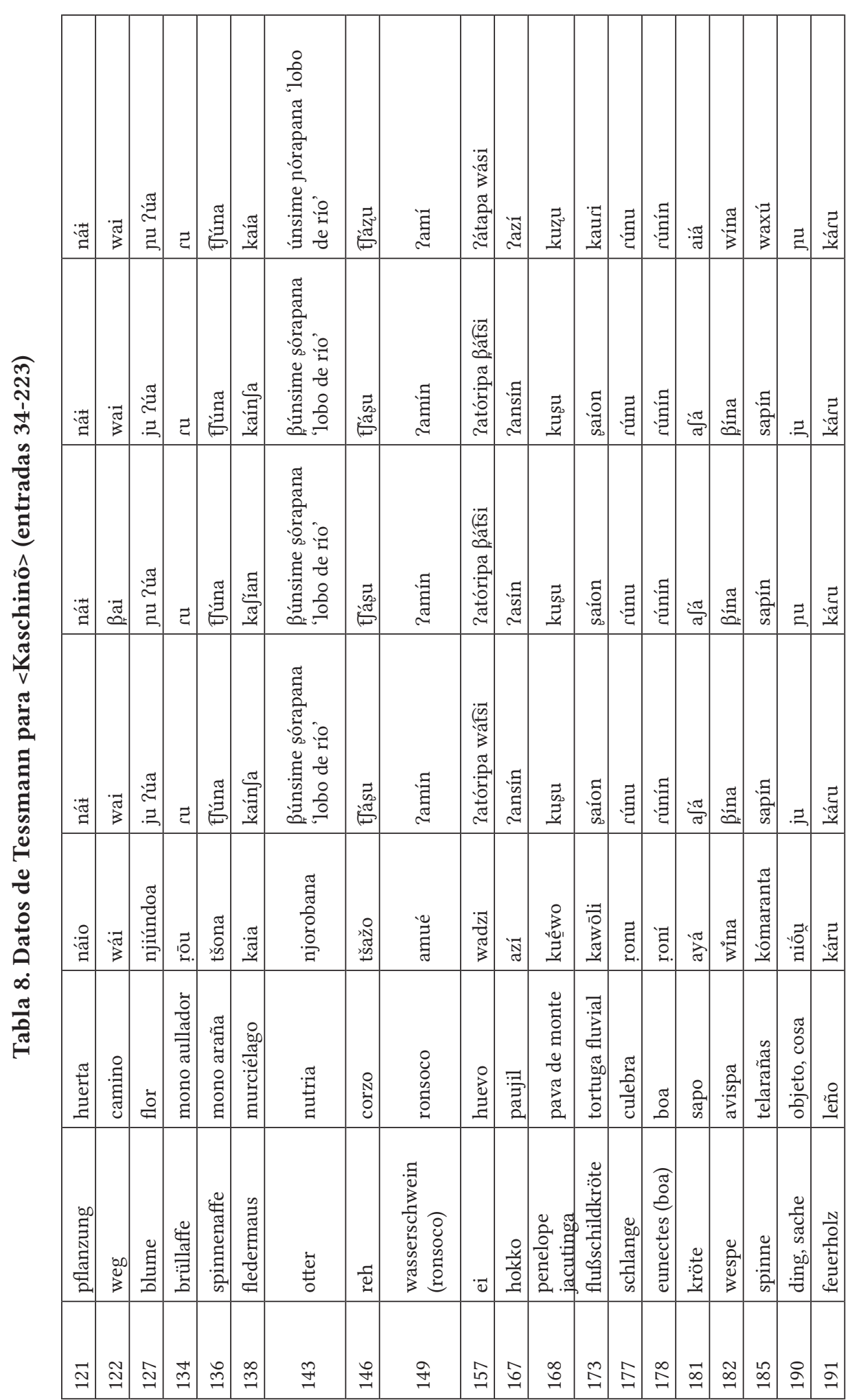




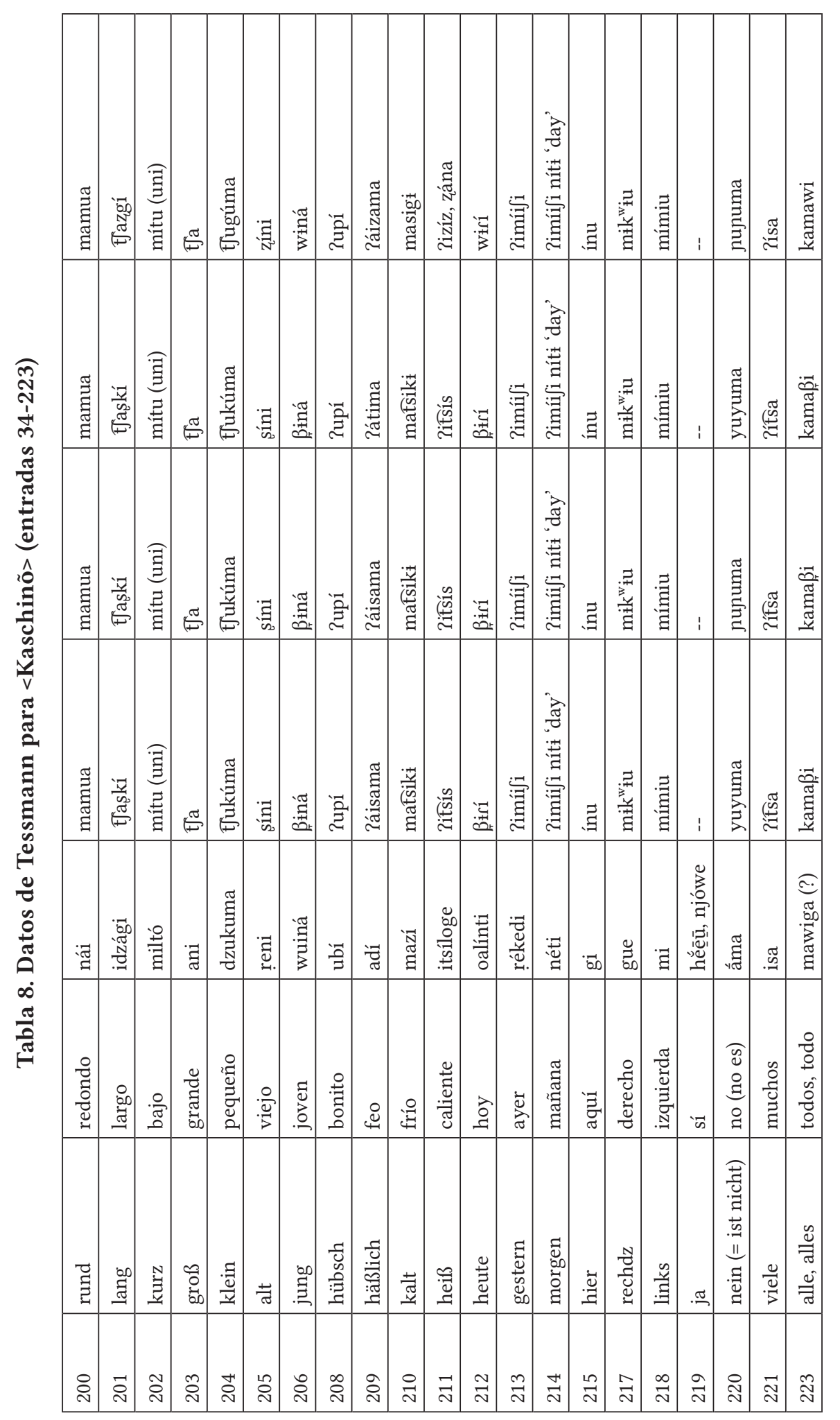




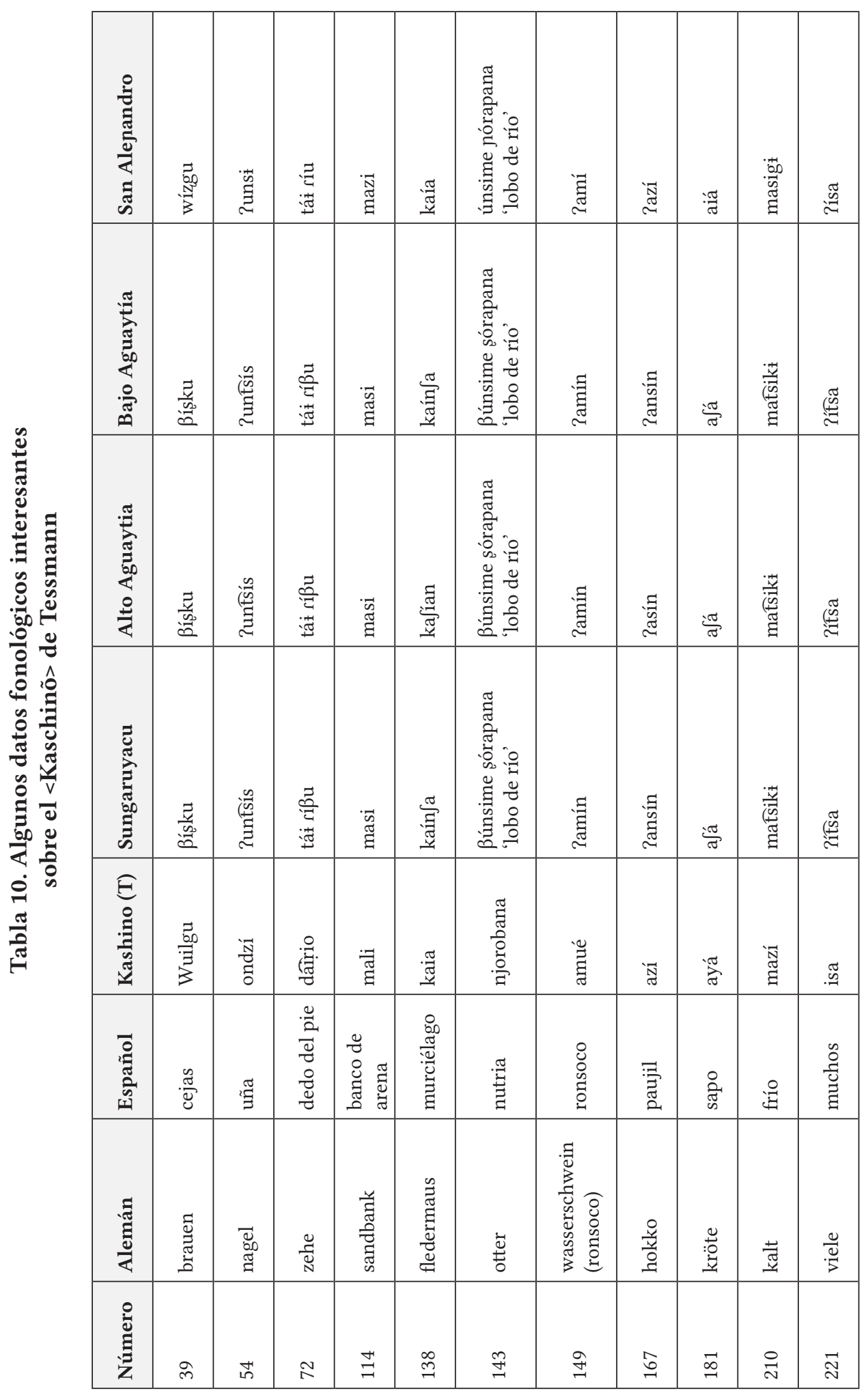


de San Alejandro: este dialecto tiende a la caída de elementos sibilantes y nasales a final de sílaba y de palabra (ver tabla 1; Zariquiey 2011b). La lista de $<$ Kaschinõ $>$ de Tessmann está llena de ejemplos que sugieren que el dialecto documentado por el etnógrafo alemán exhibía la misma tendencia. Véanse, por ejemplo, las entradas 54, 149 y 167 en la tabla 11, donde encontramos casos asociados a los procesos de caída referidos. En dichos ejemplos, la similitud entre $<$ Kaschinõ $>$ y el dialecto de San Alejandro parece ser bastante sólida, ya que el resto de dialectos contemporáneos conserva los elementos eliminados en los dos dialectos mencionados.

Un punto crucial y prácticamente indiscutible tiene que ver con la ausencia de / $/$ / en el dialecto de San Alejandro (ver tabla 1 y Zariquiey 2011b). El dialecto de San Alejandro no presenta este sonido fricativo palatal y en torno a él encontramos diversos procesos fonológicos sumamente interesantes. Entre ellos, encontramos las correspondencias entre $/ \mathrm{j} / \mathrm{o} / \mathrm{n} /$ en San Alejandro y $/ \mathrm{S} /$ en el resto de dialectos. Curiosamente, el $<$ Kaschinõ $>$ de Tessmann va de la mano con el dialecto de San Alejandro a este respecto y lo hace de manera muy sistemática. En el <Kaschinõ > de Tessmann encontramos las formas: <kaia> 'murciélago' (138), <njorobana> 'nutría' (143) y <ayá> 'sapo' (181), que se corresponden totalmente con las formas encontradas en San Alejandro (/kaía/, /nórapana/ y /ajá/, respectivamente) y difieren de las formas con / / / que encontramos en los demás dialectos contemporáneos. En nuestra opinión, este es uno de los puntos más convincentes en la argumentación presentada aquí.

Sin embargo, los datos no son siempre así de convincentes. Otro de los rasgos característicos del dialecto de San Alejandro es la deafricación de /ts/, que corresponde a /s/ en este dialecto. Los datos de $<$ Kaschinõ $>$ de Tessmann son contradictorios con relación a este punto y mientras encontramos que las entradas 210 y 221 apuntan a la existencia de un proceso similar de deafricación en el referido dialecto (ver también la sección §5.1.2), la misma lista ofrece casos que apuntan exactamente hacia la dirección contraria. Véase el ejemplo 54, incluido también en la tabla 10, pero además otros ejemplos de la tabla 8, como las entradas 157 o 211 . Es probable que cuando Tessmann documentó el <Kaschinõ >, el proceso de deafricación haya estado en pleno desarrollo y que, por lo tanto, el autor haya encontrado una situación un tanto asistemática. Si ello fuera así, los ejemplos en los que encontramos consumada la deafricación podrían acercar otra vez el $<$ Kaschinõ $>$ de Tessmann al dialecto de San Alejandro. Sin embargo, la presencia de casos sin deafricación en el corpus deja preguntas abiertas.

\section{Conclusiones}

A pesar del carácter un tanto confuso de los datos sobre los distintos dialectos de $<$ Kaschibo $>$ recogidos por Tessmann, el presente artículo ha 
mostrado su importancia innegable para la compresión de la historia del idioma cashibo-cacataibo. En primer lugar, los datos de Tessmann nos permiten comprobar la cronología de ciertos cambios que le han dado su carácter particular al cashibo-cacataibo contemporáneo. Hemos podido demostrar que este idioma tuvo /h/ hacia 1920 y que, por lo tanto, el salto glotal distintivo que presenta actualmente es fruto de un cambio lingüístico reciente. Por otro lado, hemos visto que todos los dialectos de $<$ Kaschibo $>$ podrían haber tenido $/ \mathrm{n} /$ en el momento en que Tessmann los documentó. Por lo tanto, ello sugiere que la presencia de $/ \mathrm{j} /$ en algunos de ellos podría ser un cambio reciente (probablemente motivado por el contacto con el shipibo-conibo). Finalmente, se ha podido establecer una cronología de los procesos de monoptongación totalmente consolidados en el cashibo-cacataibo contemporáneo.

En relación a la dialectología del idioma, el presente artículo muestra que los datos dialectológicos consignados por Tessmann son, en general, confusos. Sin embargo, hemos podido determinar una relación clara entre lo que Tessmann documentó y lo que tenemos en la actualidad: el <Kaschinõ > de Tessmann tiene fuertes similitudes con el dialecto contemporáneo de San Alejandro y es plausible que haya sido este dialecto el que Tessmann documentó bajo el término $<$ Kaschinõ $>$. Este descubrimiento es sorpresivo ya que este dialecto ha sido tradicionalmente llamado cacataibo y, en ese sentido, se hubiera esperado que se parezca más al dialecto que Tessmann documentó bajo el nombre $<$ Kakataibo $>$. Esta discrepancia, así como la imposibilidad de establecer relaciones sistemáticas entre el resto de dialectos contemporáneos y el resto de los dialectos documentados por Tessmann, nos deja muchas preguntas. Es probable que los datos de Tessmann no hayan sido recogidos con el rigor necesario y que estas incongruencias provengan de posibles errores del autor. Sin embargo, tal como lo señalan diversos investigadores (Gray 1953; Winstrand 1969; Frank 1994) y tal como se narra en la tradición oral del pueblo cashibo-cacataibo, la aparición y establecimiento de la figura de Simón Bolívar Odicio, un patrón cashibo-cacataibo que dedicó su vida a agrupar a los distintos clanes de ese pueblo, tuvo enormes consecuencias para la historia cultural de todo el pueblo. Es muy probable que este episodio en la vida de los cashibo-cacataibo haya tenido también consecuencias lingüísticas significativas. Un aspecto crucial de los datos de Tessmann es que el autor se contactó con los $<$ Kaschibo $>$ antes de que Simón Bolívar Odicio estableciera su dominio. Es plausible que Tessmann haya documentado lo que encontró de manera fidedigna, pero que el accionar de este hombre cashibo-cacataibo haya tenido consecuencias lingüísticas muy dramáticas y haya constituido un punto de quiebre entre lo que ocurrió antes de él y lo que encontramos en la actualidad. Las consecuencias del tiempo en que personas cashibo-cacataibo de distintos grupos estuvieron bajo el control de Simón Bolívar Odicio podrían ser la clave para entender las discrepancias que encontramos entre 
la diversidad dialectal actual y la que encontró Tessmann. Son temas, desde luego, que deberían convocar no solo a lingüistas sino también a científicos sociales y etnohistoriadores comprometidos con el conocimiento de la historia indígena de la Amazonía.

\section{Referencias}

d'Ans, Marcel. 1973. Reclasificación de las lenguas pano y datos glotocronológicos para la etnohistoria de la Amazonía peruana. Revista del Museo Nacional XXXIX: 349-369.

Brinton, Daniel G. 1891. The American race. New York: N.D.C. Hodges.

Campbell, Lyle. 1997. American Indian languages: the historical linguistics of Native America. New York and Oxford: Oxford University Press.

Cortez Mondragon, María. 1998. Cashibo-Cacataibo. In Inés Pozzi-Escot (ed.). El Multilingüismo en el Perú. Cuzco: Centro de Estudios Regionales Andinos Bartolomé de Las Casas.

Créqui-Montfort, G. de and P. Rivet. 1913. Linguistique bolivienne: Les dialectes pano de Bolivie. Le Muséon 14 (new series):19-78.

Erikson, Philippe. 1992. Uma singular pluralidad: A etno-história Pano. In M. Carneiro da Cunha (ed.). História dos Indios no Brasil, pp. 239-252. São Paulo: Companhia das Letras.

Erikson, Philippe, Bruno Illius, Kenneth Kensinger, and Maria Suelli de Aguiar. 1994. Kirinkobaon kirika (Gringo's books); an annotated Pano bibliography. Amerindia.,19, supplement 1.

Fleck, David W. 2007. Did the Kulinas become the Marubos?: A linguistic and ethnohistorical investigation. Tipití, fournal of The Society for the Anthropology of Lowland South America 5:137-207.

Fleck, David W. en prensa. Pano languages and linguistics. American Museum of Natural History: Serie monografías.

Frank, Erwin H. 1987. Bibliografía anotada de fuentes con interés para la etnología y la etnohistória de los Uni. Amazonía Peruana 8(14):151-160.

Frank, Erwin H. 1993. Los Pueblos Indios en sus Mitos 2: Uni. Quito: Abya-Yala.

Frank, Erwin H. 1994. Uni. En Fernando Santos and Frederica Barclay (eds.). Guía Etnográfica de la Alta Amazonía 2:129-237. Quito: Ediciones Abya-Yala.

Gray, Gloria. 1953. Bolivar Odicio, el Cashibo Civilizador. Peru Indígena IV.9:146-154.

Hervas y Panduro, Lorenzo. 1806. Catálogo de las lenguas de las naciones conocidas y numeración, división, y clases de estas según la diversidad de sus idiomas y dialectos, volume I. Madrid.

Instituto Nacional de Estadística e Informática (INEI). 2007. II Censo de Comunidades Indígenas de la Amazonia. http://iinei.inei.gob.pe/iinei/RedatamCpv2007.asp?ori=C 
Kensinger, Kenneth M. 1981. Recent publications in Pano linguistics. International Journal of American Linguistics 47:68-75.

Kensinger, Kenneth M. 1985. Pano linguistic, folkloristic and ethnographic research: Retrospect and prospect. In H. E. M. Klein and L. R. Stark (eds.). South American Indian Languages: Retrospect and Prospect, pp. 224-285. Austin: University of Texas Press.

Lathrap, Donald W. 1970. The Upper Amazon. New York and Washington: Praeger Publishers.

Loukotka, Čestmír. 1968. Classification of South American Indian Languages. Los Angeles: University of California.

McQuown, Norman. 1965. The Indigenous Languages of Latin America. American Anthropologist 57:501-70.

Montalvo Vidal, Abner. 2010. Los Kakatai. Etnia amazónica del Perú. Lima: IBC.

Ribeiro, Darcy and Maria Ruth Wise. 1978. Los Grupos Etnicos de la Amazonía Peruana. Lima: Instituto Lingüístico de Verano.

Ritter, Gerhard. 1986. Exposición de algunos elementos de la cultura Cashibo-Cacataibo. Yarinacocha, Pucallpa: Instituto Lingüístico de Verano.

Rivet, Paul. 1910. Sur quelques dialectes Pano peu connus. Journal de la Société des Américanistes 7:221-242.

Rivet, Paul. 1924. Langues de l'Amérique du Sud et des Antilles. In A. Millet and M. Cohen (eds.). Les Langues du Monde par un Groupe de Linguistes, Volume 16, 639712. Paris: É. Champion.

Rivet, Paul and Čestmir Loukotka. 1952. Langues de l'Amérique du Sud et des Antilles. In A. Meillet and Marcel Cohen (eds.). Les Langues du Monde par un Groupe de Linguistes. Volume 2, Second edition, 1099-1152. Paris: Centre National de la Reserche Scientifique.

Shell, Olive A. 1975 [1965]. Estudios Panos III: Las Lenguas Pano y su Reconstrucción. Yarinacocha, Pucallpa: Instituto Lingüístico de Verano.

Shell, Olive A. 1987. Vocabulario cashibo-cacataibo. Yarinacocha, Pucallpa: Ministerio de Educación e Instituto Lingüístico de Verano.

Tessmann, Günter. 1930. Die Indianer Nordost-Perus: Grundlegende Forschungen für eine systematische Kulturkunde. Hamburg: Friederichsen, de Gruyter \& Co. m.b.H. (Traducción española: 1999. Los indios del Perú Nororiental. Translated by Gunda Wierhake. Quito, Ecuador: Abyayala.)

Tournon, Jacques. 2002. La merma mágica. Vida e historia de los shipibo-conibo del Ucayali. Lima: Centro Amazónico de Antropología y Aplicación Práctica.

Valenzuela, Pilar M. 2003. Transitivity in Shipibo-Konibo Grammar. Ph.D. dissertation in linguistics, University of Oregon, Eugene.

Wistrand-Robinson, Lila. 1969. Folkloric and Linguistic Analysis of Cashibo Narrative Prose. Ph.D. dissertation. University of Texas at Austin. 
Zariquiey, Roberto. 2011(a). A grammar of Cashibo-Cacataibo. Ph.D. Dissertation. La Trobe University, Melbourne, Australia.

Zariquiey, Roberto. 2011(b). Hacia una dialectología del idioma Cashibo-Cacataibo. Lexis, 35:1. Lima: Pontificia Universidad Católica del Perú, pp. 5-46.

Zariquiey, Roberto. in press. Tessmann's $<$ Nokamán>: a linguistic characterization of a mysterious Panoan group. Cadernos de etnolinguistica.

Data recebimento: $23 / 11 / 2012$

Data aceite: 27/05/2013 